\title{
SOEP
}

SOEPpapers

on Multidisciplinary Panel Data Research

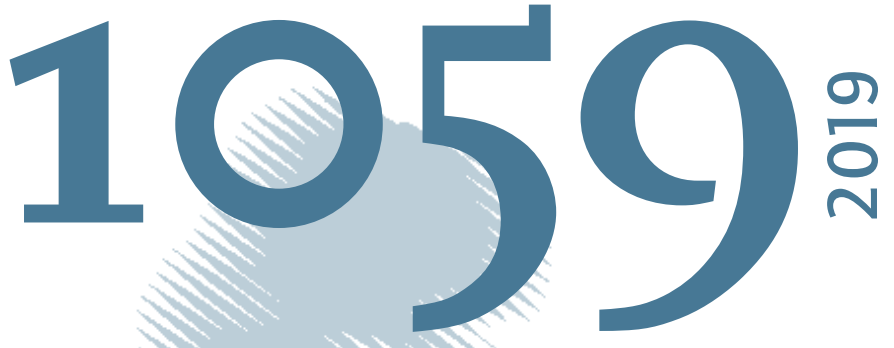

\section{The baby year parental leave reform in the GDR and its impact on children's long-term life satisfaction}


This series presents research findings based either directly on data from the German SocioEconomic Panel (SOEP) or using SOEP data as part of an internationally comparable data set (e.g. CNEF, ECHP, LIS, LWS, CHER/PACO). SOEP is a truly multidisciplinary household panel study covering a wide range of social and behavioral sciences: economics, sociology, psychology, survey methodology, econometrics and applied statistics, educational science, political science, public health, behavioral genetics, demography, geography, and sport science.

The decision to publish a submission in SOEPpapers is made by a board of editors chosen by the DIW Berlin to represent the wide range of disciplines covered by SOEP. There is no external referee process and papers are either accepted or rejected without revision. Papers appear in this series as works in progress and may also appear elsewhere. They often represent preliminary studies and are circulated to encourage discussion. Citation of such a paper should account for its provisional character. A revised version may be requested from the author directly.

Any opinions expressed in this series are those of the author(s) and not those of DIW Berlin. Research disseminated by DIW Berlin may include views on public policy issues, but the institute itself takes no institutional policy positions.

The SOEPpapers are available at http://www.diw.de/soeppapers

\section{Editors:}

Jan Goebel (Spatial Economics)

Stefan Liebig (Sociology)

David Richter (Psychology)

Carsten Schröder (Public Economics)

Jürgen Schupp (Sociology)

Sabine Zinn (Statistics)

Conchita D'Ambrosio (Public Economics, DIW Research Fellow)

Denis Gerstorf (Psychology, DIW Research Fellow)

Katharina Wrohlich (Gender Studies)

Martin Kroh (Political Science, Survey Methodology)

Jörg-Peter Schräpler (Survey Methodology, DIW Research Fellow)

Thomas Siedler (Empirical Economics, DIW Research Fellow)

C. Katharina Spieß (Education and Family Economics)

Gert G. Wagner (Social Sciences)

ISSN: 1864-6689 (online)

German Socio-Economic Panel (SOEP)

DIW Berlin

Mohrenstrasse 58

10117 Berlin, Germany

Contact: soeppapers@diw.de

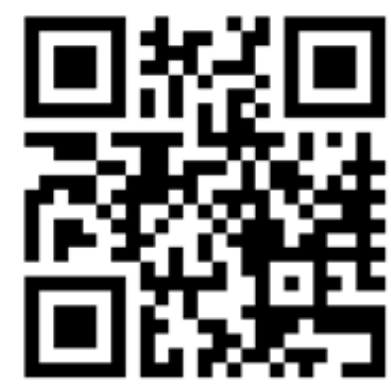




\title{
The baby year parental leave reform in the GDR and its impact on children's long-term life satisfaction
}

\author{
Katharina Heisig, ifo Institute Dresden and Technische Universität Dresden* \\ Larissa Zierow, ifo Institute Munich and University of Munich ${ }^{* *}$
}

October 2019

\begin{abstract}
This article investigates the effects of an increase in paid parental leave - twelve months instead of six months - on children's long-term life satisfaction. The historical setting under study, namely the former German Democratic Republic (GDR), allows us to circumvent problems of selection of women into the labor market and an insufficient or heterogeneous non-parental child care supply, which are issues many other studies on parental leave reforms face. Using data from the German Socio-Economic Panel (SOEP) we analyze the birth cohorts from 1980 to 1989 at adult age, and apply a difference-in-difference design making use of the very specific timing of the GDR's parental leave reforms in 1976 and 1986. We find significant and robust positive parental leave effects on life satisfaction. We also analyze whether the increase in life satisfaction is driven by a positive development of personality, health factors, schooling or labor market outcomes. Our results suggest that the increase in life satisfaction might be partially explained by personality development for individuals from low socioeconomic backgrounds and boys. For individuals from high socioeconomic backgrounds, it might be driven by a better health.
\end{abstract}

JEL Classification: J13, J22, I31

Keywords: parental leave, child care, child development, well-being, happiness, socioemotional development

\footnotetext{
* ifo Institute, Dresden Branch, Einsteinstr. 3, 01069 Dresden, heisig@ifo.de

** ifo Center for the Economics of Education, Poschingerstr. 5, 81679 Munich, zierow@ifo.de. Financial support by NORFACE through the project "The impact of childhood circumstances on individual outcomes over the lifecourse - IMCHILD" and by the DFG through the project "Multidimensional Equality of Opportunity - EOPM" is gratefully acknowledged.
} 


\section{Introduction}

Against the backdrop of increasing female and maternal labor force participation rates $^{1}$ and paternal involvement in child upbringing in many industrialized countries, providing parental leave is an important policy instrument to reconcile family and working life. Enabling young families to spend time with their newborns without giving up financial stability has proven to be an instrument to increase fertility (Lalive and Zweimüller, 2009). At the same time, child psychology literature suggests that spending more time with the primary caregiver (most often the mother) within the first year of life has a positive impact on a child's development (Bowlby 1969). Across recent economic studies, however, there is no consensus on the impact of parental leave on children's development when looking at educational, socio-emotional or health outcomes (Rasmussen, 2007; Carneiro et al., 2011; Dustmann and Schönberg, 2011; Danzer and Lavy, 2017; Huebener et al., 2018; Bullinger, 2019). ${ }^{2}$ Most importantly and to the best of our knowledge, there is no study looking at the - neither short- nor long-term - impact of parental leave reforms on children's well-being as an outcome to measure welfare. In this paper, we look at the effects of parental leave reforms on long-term subjective well-being (measured by overall life satisfaction) of children whose mothers were subject to a parental leave reform in the former German Democratic Republic (GDR). Life satisfaction serves hereby as a measure that captures the sum of effects on other individual dimensions such as health, personality and education or labor market success.

Major common methodological drawbacks of previous studies are both the selection of women into the labor market and the lack of a distinct counterfactual scenario to maternal child care. In some cases, like looking at parental leave reforms in West Germany and Austria, only a limited number of women was employed before any parental leave reform was implemented, which implies that the care situation only changed for a selective group of children (e.g., Dustmann and Schönberg, 2011; Danzer and Lavy, 2017; Huebener et al., 2018). Consequently, in those countries most children stayed at home with their mothers in the first years of life before and after the reform. In other countries with a high female labor force participation, e.g., in Norway and the US, the demand for different child care arrangements varies a lot by parental background (e.g., Carneiro et al., 2011; Bullinger, 2019). There,

\footnotetext{
${ }^{1}$ Female labor force participation rates increased in Germany from $63.3 \%$ in 2000 to $74.0 \%$ in 2017 (Austria: from $61.8 \%$ in 2000 to $71.8 \%$ in 2017 , Sweden: 76.4 in 2000 to $80.6 \%$ in 2017; it decreased in the US from $70.7 \%$ in 2000 to $62.4 \%$ in 2017) (OECD, 2019).

${ }^{2}$ A paper which is distantly related to our study is Bettinger et al. (2014) who look at medium-term educational outcomes of (indirectly affected) school-aged children, whose younger siblings are subject to a parental leave reform in Norway.
} 
parental leave reforms could imply a change from low-quality informal or formal care to maternal care for some children - as well as a change from very high-quality formal care to maternal care for others. Given these different institutional and cultural backgrounds, it is not surprising that studies using reforms and data from different countries find different effects of parental leave reforms.

In our paper we use a unique historical setting and combine it with a fitting identification strategy and dataset to overcome the problems of selection into the labor market and the high variation in childcare arrangements when analyzing the effects of parental leave. This particular context allows countries gain insights into the effects of enabling children to stay with their mother for their first year of life. We analyze a sequence of unanticipated parental leave reforms in May 1976 and May 1986 in the GDR: the so-called baby year reform. ${ }^{3}$ Before the reform, mothers were granted 26 weeks of paid parental leave, after the reform, the amount of time was doubled and mothers could stay at home for 52 weeks, i.e., a year at home with their babies. ${ }^{4}$ To evaluate the reform, we analyze the long-term effects of staying at home with the mother for the first twelve months of life — instead of only the first six months of life — on long-term life satisfaction.

The GDR might serve as a pioneer in terms of high shares of female labor force participation and providing extensive public childcare: First, almost all women were employed. ${ }^{5}$ Second, child care — standardized full-day care for all children aged up to six years — was organized and supervised by the government. ${ }^{6}$ There was almost no variation between available childcare facilities and thus no selection of specific groups of children into particular forms of childcare.

For causal identification of the effects, we use the very specific timing of the baby year reform: the reform of 1976 was targeted at parents with at least two children and was extended in 1986 to all parents regardless of the number of children. The sequential implementation enables us to employ a difference-in-differences approach (DiD). We compare outcomes of firstborn children born before (not treated) and after (treated) the reform of 1986. To isolate

\footnotetext{
${ }^{3}$ Eligible parents were mothers and fathers. However, since almost no fathers made use of the baby year (Groeben, 2011), we argue, in this paper, that we estimate the effects of a mother's extended parental leave on child outcomes.

${ }^{4}$ The reforms granted $70-90 \%$ of the eligible parent's wage (height of sick pay) and job protection within the time frame of parental leave (Braun and Klein, 1995).

${ }^{5}$ In $1989,91.2 \%$ of all women in the GDR were employed or in training. Excluding trainees and university students, the share of female labor participation was still as large as $78.1 \%$ in 1989 (Winkler, 1990).

${ }^{6}$ Public childcare was complemented by after school centers for children between six and ten years of age. In 1986, a place in after school centers was available for $83.3 \%$ of all children of this age group (Braun and Klein, 1995).
} 
the effects of the policy reform, we use children born in the same time period, but who have older siblings (referred to as later-borns), as a control group. We chose this specific subgroup since later-borns were already treated by the reform of 1976 and were thus unaffected by the reform of 1986. The most important identification assumption in our approach is the one of common trends of firstborn children and children with older siblings regarding the birth cohorts 1980-1989. We provide evidence that this assumption holds.

To estimate the DiD framework we use the German Socio-Economic Panel (SOEP), which is a representative sample of all people living in Germany. We draw upon the SOEP waves of 2000 to 2016 and observe individuals who were born between 1980 and 1989 and raised in the GDR. The SOEP includes all necessary information for our identification strategy, namely an individual's birth year and month and whether or not they have siblings. It also includes the sibling's birth date, which allows us to define the baby year eligibility status of an individual's mother. The SOEP data does not contain information on the take-up rate of the baby year. Given evidence from other sources, we know that $95 \%$ of all mothers made use of the baby year in the late 1980s (Höckner, 1995). This indicates that almost every eligible mother made use of the baby year - meaning that almost every eligible child was affected by the reform. Strictly speaking, however, we estimate an intention-to-treat effect of the reform.

Results show that spending more time with the mother in the whole first year of life compared to spending six months with the mother and six months in a childcare center matters for individuals in the long run. The prolongation of the parental leave by six months has positive effects on life satisfaction, which increases by $33 \%$ of the standard deviation and thus corresponds to an increase by $7.8 \%$ of the pre-reform mean. Results are robust throughout sensitivity analyses and effects are not different for females and males, as well as individuals from high and low socioeconomic backgrounds.

Furthermore, we analyze whether the increase in life satisfaction might be driven by channels that could have been influenced by the baby year reform as well, such as personality development, health and educational or labor market outcomes. Overall, we find that the positive effect on life satisfaction might be partly explained by a positive development of personality traits of individuals from low socioeconomic backgrounds and boys. For individuals from high socioeconomic backgrounds, it could be partly explained by an increased health of individuals.

To the best of our knowledge, there are no papers so far that analyze the effects of parental leave reforms on life satisfaction or related socio-emotional outcomes apart from Huebener et al. (2018), who only look at short-run socio-emotional outcomes and find no sizable effects. 
However, it seems very likely that more time with the mother in the first months of life has an impact on children's socio-emotional outcomes. When mothers return to work within twelve weeks after giving birth, Berger et al. (2005) find an increase in problematic behavior in children. Further empirical studies find that parental bonding and minimizing stress factors is important for a child's development (Kottelenberg and Lehrer, 2014; Beeghly et al., 2017; Golding and Fitzgerald, 2017; Schore, 2017).

Also, to the best of our knowledge, there has not been an analysis of the long-term health effects of parental leave reforms. However, in terms of short-term health outcomes, Ruhm (2000) find that more generous paid parental leave rights across nine European countries in a period between 1969 and 1994 reduce the mortality rate of infants and young children. Also, Bullinger (2019) finds positive short-term health effects in terms of a reduction in asthma of children, but no significant effects on respiratory or food allergies. In contrast, Baker and Milligan (2008) find almost no impact of a prolonged paid maternal leave reform in Canada from six to twelve months on children's health, although the breastfeeding duration increased. On the other hand, Carneiro et al. (2011) find that prolonged maternal leave reduces teenage pregnancy.

In regards to cognitive skills, however, finding almost no statistically significant effects of parental leave reforms is in line with many previous papers. Danzer and Lavy (2017) find no overall effects of a parental leave extension from 12 to 24 months of 1990 in Austria on cognitive outcomes, but subgroup analyses for gender and maternal education reveal strong heterogeneity. Rasmussen (2007) finds no measurable long-term effects for a paid leave reform in Denmark of 1984 that increased leave length after birth from 14 to 20 weeks. Dustmann and Schönberg (2011) analyze three major parental leave expansions in West German states. ${ }^{7}$ They find no measurable effects that expansions in leave coverage improves children's cognitive outcomes. If anything, they find that the expansion in unpaid leave reduced the probability of completing high-track schools. Huebener et al. (2018) find no effects on children's short-term cognitive outcomes for a reform in Germany in 2007 that expanded paid leave in the first year and removed it in the second year after childbirth. In contrast to that, Carneiro et al. (2011) find evidence for Norwegian parental leave reforms which affected children's long-term cognitive outcomes positively. Carneiro et al. (2011) exploit a maternity leave reform in Norway in 1977 extending paid leave from 12 to 18 weeks and up to one year of unpaid leave for mothers.

\footnotetext{
${ }^{7}$ The three reforms are prolongations from two to six months in 1979, from six to ten months in 1986, and an unpaid parental leave expansion from 18 to 36 months in 1992. Note that in this period West German states were characterized by low female employment rates and a high share of part-time working women.
} 
Our paper contributes to the parental leave literature in at least three different ways: First, making use of a setting in which the reform indeed significantly changed the maternal care situation of very young children who all shared a very similar counterfactual care situation. This reassures us that we estimate the pure effect of staying at home with the mother instead of being in a child-care center - without mixing up the reform effect with selection of mothers into the labor market and the choice of a certain child care quality.

Second, we implement a DiD-approach making use of the particular reform timing to estimate causal effects of the reform. The common trend assumption only requires a common trend in outcomes of firstborn children versus children with siblings in absence of the reform, a scenario that is very likely given. We are thus able to causally identify the parental leave reform effect without strong assumptions regarding, e.g., common trends across states. In this setting, using a DiD-approach is more suitable than a random discontinuity design (RDD), since we think that a pre-post-comparison - even if done very close around the cut-off would not lead to results that are causally interpretable. This is due to the fact that in 1986, the GDR was already in turmoil which resulted in the German reunification. Also, importantly, the Chernobyl disaster occurred on $26^{\text {th }}$ of April 1986, which overlaps with the baby year reform. ${ }^{8}$

Third, to the best of our knowledge, this is the first study analyzing long-term effects of parental leave reforms on life satisfaction, although recent economic literature increasingly focusses on individual measures of well-being (e.g. Kahneman and Krueger, 2006; Clark et al., 2008; Deaton and Stone, 2013; Benjamin et al., 2019). Specifically, we measure life satisfaction when individuals are 18 to 36 years old, i.e., we investigate whether longer parental leave has a long-lasting impact on overall well-being.

The remainder of this study is structured as follows: the next section describes the background and institutional setting of the GDR, in which the baby year reform took place, as well as our hypotheses. Sections 3 and 4 introduce the empirical approach and our data, respectively. Section 5 presents our main findings for life satisfaction as outcome variable, sensitivity and effect heterogeneity analyses. Here, we also check whether effects on life satisfaction are driven by personality, health or schooling and labor market outcomes. Section 6 discusses and Section 7 concludes our findings.

\footnotetext{
${ }^{8}$ Additionally, by applying a DiD approach we can circumvent the problem of birth delaying, which other papers on parental leave reforms do face.
} 


\section{Background and institutional setting}

\subsection{The pre-reform scenario of the baby year reform of 1986}

In socialist countries such as the GDR, gender equality was said to be acquirable only through women's participation in the labor market. Women were therefore encouraged by government to participate in higher education and in the labor market. However, until the 1950s mostly single women were employed in the GDR. From the 1960s on, the government saw the need to increase female labor market participation due to economic circumstances, ${ }^{9}$ and increasingly targeted married women as well. Various policies (e.g., law on maternity and child protection of 1950, family code of 1965, law on abortion of 1972) were introduced to promote women's rights and working women, which led to very high female labor force participation rates compared to other countries, such as former West German states (Obertreis, 1986): excluding trainees and university students, the average share of female labor force participation was as large as $83.8 \%$ in 1979 and $85.8 \%$ in 1989 (Winkler, 1990), compared to 53.6\% in 1979 and $58.0 \%$ in 1989 in former West German states (OECD 2019).

Figure 1

Female employment rates in \% per age group in the GDR and former West German states, 1979 and 1989

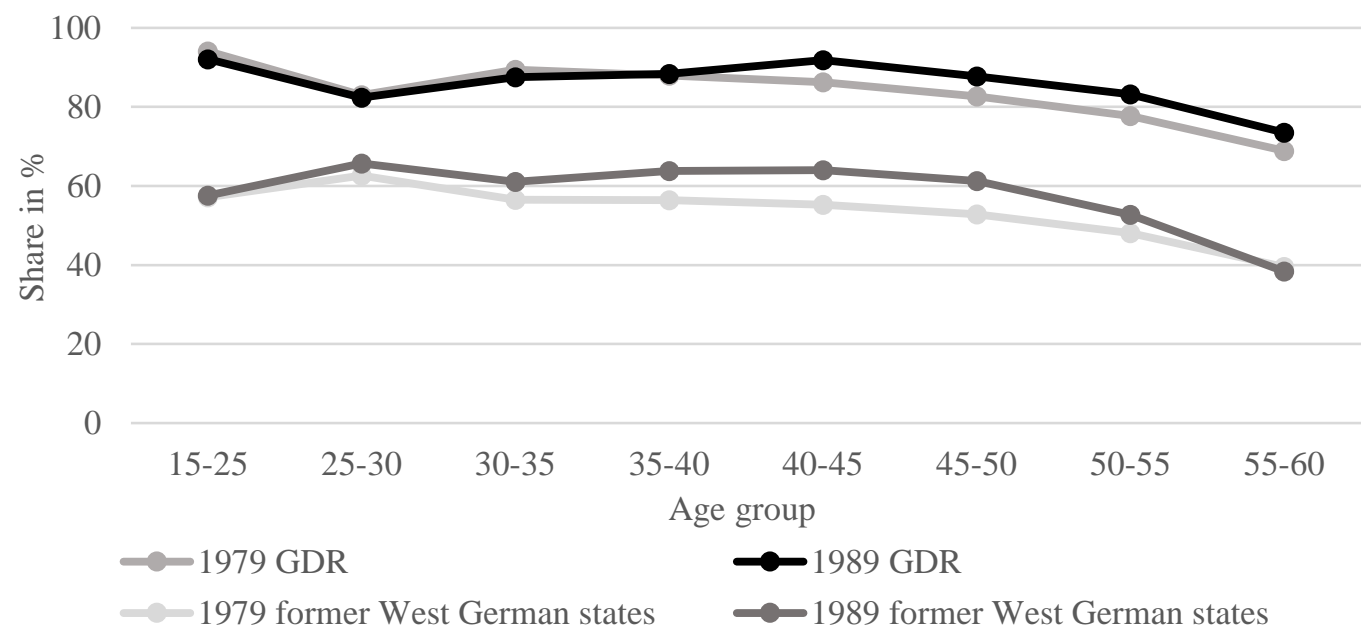

Notes: Displayed are employment rates in \% per age group of working-aged women in the GDR and former West German states for the years 1979 and 1989. The shares do not include women in education or training. Also, women were classified as pensioners with an age of 60 years and are thus not shown in this figure.

Source: Winkler (1990), OECD (2019).

\footnotetext{
${ }^{9}$ First, $45 \%$ of all manufacturing plants in the GDR were destroyed in the war, compared to $20 \%$ in the former West German states. Second, the GDR had to pay roughly 25bn German Mark as war reparations to the USSR. Third, the working aged population decreased from roughly $12 \mathrm{~m}$ individuals in 1949 to $10.5 \mathrm{~m}$ individuals in 1960 due to a large number of people who moved to the old West German states before the building of the Berlin Wall in 1961 (Obertreis, 1986).
} 
Figure 1 shows that the high female labor force participation rates in the GDR were no phenomenon of specific age cohorts, but visible throughout the age distribution. The highest share is reached for women aged 15 to 24 with $94.1 \%$ in 1979 . Worth mentioning is that the average age of women when giving birth to the first child between 1970 and 1989 was 22.4 years, meaning that almost all women were employed when giving birth to their first child.

The large majority of female employees, namely $73 \%$, were employed full-time. ${ }^{10}$ Mothers were no exception: between $72.4 \%$ and $84.6 \%$ of all employed mothers were employed fulltime. This ratio is rather large in comparison to the former West German states, where the range was between $29.9 \%$ and $36.9 \%$. Out of all full-time employed women, $75.1 \%$ (GDR) and $73.8 \%$ (former West German states) had no children (Höckner, 1995). Also, in the GDR, most mothers went back to work within roughly 26 weeks of giving birth, when maternal leave ended (Israel and Kerz-Rühling, 2008).

However, unlike labor force participation, the GDR was no exception regarding fertility: as in all developed countries, fertility started decreasing sharply in the late 1960s. To counteract this development, the GDR introduced the first baby year reform in 1976 through which mothers of later-borns became eligible for one year of job-protected paid parental leave to reconcile family and labor market participation. In the reform's aftermath, short-term fertility increased temporarily, but further declined from 1980 onwards - as did fertility rates in most other industrialized countries. In the aftermath of the reform in 1986, fertility rates did not respond (Büttner and Lutz, 1990). This is important for our empirical analysis, since in a setting with increasing fertility rates we would not be able to disentangle effects of the parental leave reform from the effects of an increased fertility.

Just like female labor force participation, public childcare availability in the GDR was also large compared to other countries: ${ }^{11}$ In $1989,60 \%$ of all newborn-to three-year-old children and $80 \%$ of all one-to three-year-old children were cared for in public child care centers, which were the most basic stage of the educational system and administrated by the health ministry. Almost all newborn-to three-year-old children attending child care centers were there on a full-time basis, namely $86.4 \%$, and childcare on a half-day basis was uncommon in the GDR (Helwig, 1987; Braun and Klein, 1995). Furthermore, informal care by nannies was extremely rare. Also, most grandparents, neighbors or friends of mothers were working full-time as well,

\footnotetext{
${ }^{10}$ The data refers to 1990 . However, we found no evidence that the share of women working full-time was smaller before the expansion of the baby year reform in 1986.

${ }^{11}$ Childcare attendance in the GDR in the 1980s was roughly as large as childcare attendance in Western countries nowadays. In 2016, Denmark had the highest enrolment rates in early childhood education and care services of newborn-to two-year-olds with ca. $62 \%$ and Belgium as well as Iceland with ca. 60\% (OECD, 2018).
} 
which is why they were not able to assist with childcare regularly (Zwiener, 1994). ${ }^{12}$ Thus, in contrast to other studies, we face no issue of specific sorting into childcare in our setting. ${ }^{13}$

\subsection{The post-reform scenario of the baby year reform of 1986}

To counteract decreasing fertility rates in the 1980s, the baby year was extended to all mothers. The new reform was announced in mid-April and implemented on the first of May, 1986. From then on, parents of firstborn children became eligible for one year of job-protected paid parental leave as well (70-90\% of their wages, depending on the amount of sick pay) (Braun and Klein, 1995). Firstborns were then able to spend the entire first year of life with their mother instead of only the first six months. Data shows that most eligible mothers made use of the baby year: up to $95 \%$ in the late 1980s (Höckner, 1995). Thus, the introduction of the baby year in 1986 changed the most common care mode for children aged six to twelve months from childcare centers to maternal care. In 1988, only $1 \%$ of all children below the age of one year were still cared for in child care centers (Israel and Kerz-Rühling, 2008). ${ }^{14}$

\subsection{Counterfactual care mode vs. parental care mode}

The alternative care mode to parental care within the first year in a child's life in the GDR was public formal care. Centers were supervised by the health ministry. Available were daycare centers (in 1989, 97.7\% of all available places), which were open from six am to six pm on a weekday; week-care centers, which opened 24 hours on a weekday $(1.3 \%$ of all available places), and children's homes (1\% of all available places). Most childcare centers were public or operated by municipalities, about $5 \%$ were operated by state-owned enterprises. There were no independent and almost no church-operated childcare facilities, nannies or other informal care (Zwiener, 1994).

\footnotetext{
${ }^{12}$ In contrast to the circumstances in the GDR, in former West German states in the 1980s, $70 \%$ of children younger than six years old of working women spent their mornings in public care, $21 \%$ with grandparents, and $7 \%$ with neighbors or parent's friends. Furthermore, the share of available child-care places for children younger than three years of age was as little as 1.6\% and 1.8\% in 1986 and 1990, respectively (Braun and Klein, 1995.

${ }^{13}$ Only a very small number of children was queuing for places in childcare centers: in 1989, 360.000 places were available. 30.000 applications (roughly $7.7 \%$ of all applications) in total could not be satisfied immediately (Zwiener, 1994). Within the waiting time, if possible, children were mostly cared for by grandparents, siblings, neighbors.

${ }^{14}$ It might be argued that mothers self-selected into applying for the baby year (mothers who were able to afford $10-30 \%$ less income). However, the framework of high female labor force participation rates before and after the reform on the one hand and high childcare attendance before and low attendance after the reform on the other hand makes us confident that there was no self-selection. Another foundation for this assumption is the unmatched equality of income in the GDR: the Gini coefficient was as small as 0.22 in 1980 and 0.20 in 1987 (West German states: 0.32) (Galbraith et al., 2017). This implies a comparatively small income inequality and thus a small probability that a specific group of mothers selected themselves into applying for the baby year.
} 
Since childcare centers were required to adhere to strict regulations, quality did not vary significantly throughout the centers, guaranteeing similar conditions for all children. The focus of the childcare center's programs was to foster children's health, which was supervised by pediatricians, ${ }^{15}$ and enhance cognitive development. Children were meant to have the opportunity to play, learn to handle everyday situations and develop positive relations with teachers and other children. The aim of these measures was to encourage the development of senses, perception, cognitive activity, language acquisition, and moral values (Zwiener, 1994). All pre-school teachers underwent a three-year theoretical and practical training at a medical vocational school and specialized in subjects such as early childhood education, psychology, and pediatrics. Starting in 1983, students in psychology were also able to specialize in the field of "childcare center psychology" in order to improve psychological supervision in childcare centers (Zwiener, 1994). In sum, this provides evidence that child care centers' staff quality was rather high. However, the group size varied between five or six children per teacher in daycare centers which was considered rather large. In practice, group sizes were often even larger due to absent days of teachers (Nentwig-Gesemann, 1999).

In terms of our identification strategy, one might be concerned that childcare quality (e.g., group size) improved due to the baby year reform, since almost all children below one year of age were not cared for in public childcare anymore (Israel and Kerz-Rühling, 2008). Moreover, the continuing decrease in total fertility rates during the 1980s could have intensified the development. In case of a constant or less decreasing number of childcare places, this might have resulted in improved group sizes. However, the care ratio per 1000 children stayed fairly constant between 1986 and 1989: The care ratio per 1000 children slightly decreased from 811 to 802 children in care (Winkler, 1990; Zwiener, 1994). Thus, the baby year reform might have only had a marginal effect on the quality of the childcare system.

\subsection{Hypotheses}

With the introduction of the baby year, public childcare was substituted by maternal care for children aged six to twelve months. Our analysis focuses on the outcome variable of life satisfaction as an aggregate measure of personality development, health, and school or work life. If the overall measure of the latter three dimensions improves, life satisfaction should be positively affected as well. Or, in other words - if we find an effect of the baby year on life

\footnotetext{
15 Doctors were also responsible for sanitary tasks and the consulting and training of teachers and parents (Zwiener, 1994).
} 
satisfaction, there are most likely effects on some of the assumed channel variables as well. This is because longer parental leave might have affected children in several ways.

First, parents play a crucial role in fostering children's socio-emotional development. Attachment theory postulates that separating an infant or toddler from the mother causes anxiety (Bowlby, 1969). Spending a whole day in care centers in groups with other children may cause a lot of emotional stress, from which they need to recover. There could be differences in the way mothers are capable of offering their child the necessary emotional support after returning from work. This might particularly be the case for lower-educated mothers who are likely to work in low-wage jobs. These also tend to be jobs that expose workers to physical hazards and psychological stress - factors known to correlate negatively with good parenting and child development (e.g., McLoyd, 1998; Raver, 2003; Han, 2005; Johnson et al., 2005; Felfe and Hsin, 2012; Felfe and Zierow, 2018). Therefore, we hypothesize that especially children from low socioeconomic backgrounds benefited from the prolonged parental leave in terms of life satisfaction. In contrast, higher-educated mothers who tend to be in better job positions might be more capable of spending quality time with their children in the remaining hours after work. Therefore, for children from high socioeconomic backgrounds, we expect - in view of existing literature (Felfe and Hsin, 2012; Felfe and Zierow, 2018) positive or no effects of the prolonged parental leave on life satisfaction through the channel of personality development. We also expect positive effects especially for boys, who tend to benefit more than girls from maternal attachment in early life. For example, Beeghly et al. (2017) show that boys, but not girls, are vulnerable to early caregiving risks such as maternal depression, resulting in a decreased mother-child attachment security in toddlerhood. We therefore hypothesize that an increase in life satisfaction might emerge through the channel of personality development.

Second, the program of care centers was mainly aimed at maintaining and enhancing children's health and cognitive development. Thus, the staff followed a strict program that was similar throughout the GDR, resulting in almost uniform quality throughout the care centers. Attending child care may thus have exerted positive effects on these dimensions. Yet, this also implies that the baby year reform might have decreased health and cognitive outcomes if the quality in care centers exceeded the quality of care at home. Children of lower-educated mothers might face worse environments for health and cognitive development at home compared to the GDR's child care centers. Thus, we also hypothesize that the baby year might have led to negative effects on life satisfaction for children of lower-educated mothers through the channels of health and education (e.g., Loeb et al, 2004; Belsky et al., 2007). There might 
be no or positive effects on life satisfaction through the channels of health and education for children from higher-educated mothers, since their environment for health and cognitive development might have been similar or better than that of care centers.

\section{Empirical approach}

The setting under study facilitates causal identification of the reform effect on long-term life satisfaction for two major reasons: First, almost all women were employed in the GDR, child care was standardized full-day care for all children aged up to six years, and there was almost no variation between available childcare facilities and thus no selection of specific groups of children into particular forms of childcare. Second, the reform of 1986 guaranteed all mothers one year of paid parental leave, and we know that almost all mothers made use of it. We take advantage of the sequential introduction of the reforms (see Figure 1 in Section 2) and apply a DiD-approach by comparing the difference between the outcomes of firstborns born before and after the reform in May 1986 with the difference between the outcomes of later-borns before and after the reform in May 1986. ${ }^{16}$ The dataset which fits the setting and empirical approach is introduced in Section 4.

Figure 2

Treated and not treated individuals of the GDR's baby year reform

\begin{tabular}{|l|c|c|}
\hline \hline & Reform 1976 & Reform 1986 \\
\hline Firstborn children & not treated & treated \\
\hline Later-born children & \multicolumn{2}{|c|}{ treated (since 1976) } \\
\hline
\end{tabular}

Notes: We observe an intention-to-treat effect, since we do not know whether the mother actually made use of the baby year.

Importantly, the implementation of the reform of May 1986 was unexpected. Therefore, we can rule out that the timing of birth was affected by the reform. We restrict the analysis to individuals born between 1980 until 1989 to be far enough from the 1976 reform and close enough to the 1986 reform. We also do robustness checks reducing and increasing the number of birth cohorts under study, which however, does not lead to major changes in the results.

A further important issue is the intention-to-treat-nature of our estimates, since we do not know from the survey data whether or not mothers made use of the paid parental leave or whether or not mothers were employed before birth. However, given the institutional setting

\footnotetext{
${ }^{16}$ Firstborn and later-born children in our sample are not members of the same family.
} 
of the GDR (high female labor force participation, standardized full-day childcare, take-up rate of the baby year of up to 95\%), it is very likely that most eligible children were treated by the reform.

There are two main reasons why applying a DiD-approach rather than a pre-postcomparison by using a random discontinuity design is preferable in our specific case. First, the Chernobyl disaster occurred on the $26^{\text {th }}$ of April 1986 - only a few days before the baby year reform came into force. Since the disaster affected the health of children and adults severely (see, e.g., Cardis et al., 2006), it might influence our findings when just comparing pre- and post-reform cohorts. However, the disaster affected children regardless of the number of siblings they already had, i.e., our DiD-approach should not be affected by this event. Second, the baby year reform is very close to the date of the fall of the Berlin Wall in 1989 and the German reunification in 1990. Even before these events took place there was turmoil in the GDR, which might have influenced child investment decisions of parents, for example regarding education. However, already born children were affected equally by these developments regardless of their number of siblings. Taken together, in contrast to pre-post comparisons, our DiD-approach should work much better for the evaluation of effects of the GDR baby year reform.

For applying a DiD-approach, we must be sure that the trend of life satisfaction of firstborn and later-born children (all born between 1980 to 1989) would have been the same in absence of the reform. Graphical evidence for the common trend is shown in Figure 4. There might exist scenarios which would violate the common trends assumption. First, mothers might have postponed birth to be eligible for the reform, which affects many other studies using birth date cut-off rules. However, this does not affect our study for two reasons. One, it is only a major concern in the case of a random discontinuity design, since these studies use a narrow time frame around reforms. Two, our sample of individuals born in April to June of 1986 is very small. Furthermore, we exclude all individuals born in 1986 to address this issue in a sensitivity analysis. However, results for life satisfaction outcome are robust. Second, care quality in public childcare centers might have changed after the 1986 reform. This would occur if the child care ratio would decrease, since most children below one year of age were now kept out of childcare. However, as explained in Section 2.4, the number of places in childcare as well as the care ratio per 1000 children stayed fairly constant between the years 1986 and 1989 . Third, it would be problematic for our approach if our control group had been treated by the reform of 1986 as well. If a younger sibling was born within the first year of life of their older sibling, they would potentially be affected by the reform of 1986 . However, we can rule out 
this concern due to two reasons: One, biological factors make it uncommon for siblings to be less than 12 months apart. Two, the concern of siblings being affected ${ }^{17}$ although they were not eligible themselves might also hold if children were able to stay at home with their mother (firstborns as well as later-borns) when a younger sibling was born. However, this concern does not affect our study, since "children having a younger sibling" fall under the category of "laterborn children" and thus have already had the chance to stay at home with their mother for their first year of life since 1976. For them, nothing changed after the reform of 1986. Furthermore, we are unaware of any other family policy or labor market reform during the time under study. In any case, potentially occurring reforms would have occurred at the state level and would thus be captured by birth cohort fixed-effects. Thus, we estimate the following DiDspecification:

(1) $y_{i j m}=\lambda$ (Firstborn $)_{j m} \times(\text { Postreform })_{j m}+\beta_{1}(\text { Firstborn })_{j m}+\beta_{2}$ (Postreform $)_{j m}+\pi_{j}+$ $\mu X_{i}+c+\epsilon_{i j m}$.

$y_{i j m}$ is the measure for long-term life satisfaction in later adult life of the child. The interaction effect between (Firstborn) ${ }_{j m}$ and (Postreform) ${ }_{j m}$ identifies all firstborn children whose mothers were affected by the reform and thus eligible to one year of paid parental leave with their firstborn child. $\lambda$ is the coefficient of interest and measures the intention-to-treat effect. $\pi_{j}$ measures year of birth fixed-effects. (Firstborn) ${ }_{j m}$ is a dummy indicator for children who are a firstborn child and the coefficient $\beta_{1}$ captures all possible permanent and general differences between children who were born as firstborns or as later-borns. (Postreform) ${ }_{j m}$ is a dummy indicator for children who were born on or after the $1^{\text {st }}$ of May 1986, and the coefficient $\beta_{2}$ captures all possible differences between children who were born before and after the reform. Additionally, the vector $X_{i}$ contains individual and parental control variables. $c$ is the constant, and $\epsilon_{i j m}$ is the heteroskedasticity-robust error term. We estimate the differences in outcome change before and after the reform between firstborns and later-borns:

(2) $\hat{\lambda}=\left(\bar{y}_{\text {Firstborn,post }}-\bar{y}_{\text {Firstborn,pre }}\right)-\left(\bar{y}_{\text {Higherborn,post }}-\bar{y}_{\text {Higherborn,pre }}\right)$.

\footnotetext{
17 That older siblings of affected children might also be affected by a given parental leave reform is shown in Bettinger et al. (2014).
} 
Equation (2) displays the difference in average long-term life satisfaction of children born after the reform versus before, whose mothers were eligible for the reform (firstborns) less the difference in outcomes of children born before and after the reform who were not subject to the reform (later-born children).

We also estimate whether there are differences in the effect of the baby year reform between subgroups (socioeconomic background of the individual - measured by maternal education - or gender). Therefore, we estimate the following DID-specification with additional interactions. Equation (3) shows the specification for analyzing differences between individuals by socioeconomic background:

(3) $y_{i j m}=\lambda_{\text {edu }}$ (Firstborn $)_{j m} \times(\text { Postreform })_{j m} \times(\text { Low maternal education })_{j m}+$

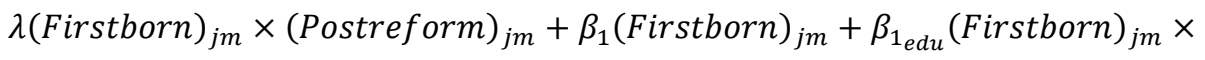
$(\text { Low maternal education })_{j m}+\beta_{2}(\text { Postreform })_{j m}+\beta_{2_{e d u}}(\text { Postreform })_{j m} \times$ (Low maternal education $)_{j m}+\pi_{j}+\mu X_{i}+c+\epsilon_{i j m}$

Equation (3) is almost identical to equation (1), but additionally interacts the variable for the interaction effect, postreform-borns and firstborns with a dummy for a child's socioeconomic background (maternal education). For analyzing whether there are differences in the effects for each gender, the variable for the socioeconomic background is substituted by a dummy for male gender.

\section{Data and descriptive statistics}

\subsection{Data}

Our analysis is based on the SOEP, which is a representative sample of all people living in Germany (Goebel et al., 2019). We draw upon the SOEP waves of 2000 to 2016 and observe individuals who were born between 1980 and 1989 and raised in the GDR to cover a sufficient timeframe around the reform of $1986 .{ }^{18}$ The SOEP includes all necessary information for an identification strategy that allows us to estimate causal effects of prolonged parental leave on children's long-term life satisfaction and possible channels. To measure long-term outcomes,

\footnotetext{
${ }^{18}$ Generally, data of individuals born in later years is used from more recent SOEP waves to ensure we observe adult individuals.
} 
we restrict our main sample to adults above 18 years of age ${ }^{19}$ for whom we have information on birth year and month as well as the necessary information on siblings.

Treatment: Our treatment variable is unity for all firstborn children who were born on or after the $1^{\text {st }}$ of May, 1986. Before the reform, firstborn children were the sole group of individuals who could only spend their first 26 weeks with their mother instead of the entire first year of life. However, this changed with the $1^{\text {st }}$ of May 1986. The treatment variable takes the value zero for all other groups of individuals, since the group of firstborns was the only group eligible for the baby year reform of 1986.

Life Satisfaction and channel measures: The SOEP provides us with measures for life satisfaction and potential channel variables in terms of personality, schooling or labor market and health. Life satisfaction is a self-assessment variable and varies between zero and ten, where zero is fully unsatisfied and ten is fully satisfied. In terms of personality development, we focus on the established measure of the Big Five personality traits that consist of five dimensions: agreeableness, conscientiousness, extraversion, neuroticism and openness (see Figure 3). We use the ten-item short version of the Big Five inventory (each personality trait is calculated from two variables), but include three variables instead of two variables to calculate the agreeableness personality trait to increase validity, as was suggested by Rammstedt and John (2007).

Figure 3

Big Five personality traits and underlying variables

\begin{tabular}{ll}
\hline \hline Agreeableness & \\
\hline Conscientiousness & $\begin{array}{l}\text { Has a forgiving nature; is considerate and kind to others; is sometimes somewhat } \\
\text { rude to others (reversed) }\end{array}$ \\
\hline Extraversion & Does a thorough job; tends to be lazy (reversed) \\
\hline Neuroticism & Gets neing and sociable; is reserved (reversed) \\
\hline Openness & Values artistic, aesthetic experiences; has an active imagination \\
\hline \hline
\end{tabular}

Source: Gerlitz and Schupp (2005), Rammstedt and John (2007).

For the health channel, we concentrate on measures previously found in the literature to be affected in the short-term by maternal leave and maternal employment. These are overall health, obesity, and chronic illnesses (e.g. asthma, autoimmune diseases, hypertension, etc.). The self-assessment question of current health situation is coded one to five, where one is the

\footnotetext{
${ }^{19}$ The variable for class repetition is drawn from the youth questionnaire of the SOEP. Thus, answering individuals were 16 to 19 years old.

${ }^{20}$ In contrast to the list of variables used for the ten-item short version of the Big Five inventory as stated in Rammstedt and John (2007), in the SOEP, there is no "is generally trusting"-variable given. Here, the third variable for the agreeableness trait is "has a forgiving nature".
} 
best and five is the worst possible value. Individuals are obese when their body-mass-index equals or exceeds a value of 30 . We use a binary variable to classify individuals as obese (unity), or not (zero). The binary variable of having chronic illnesses takes the value of unity when the individual is diagnosed with any chronic illness and zero otherwise. For the channel of schooling and labor market outcomes, we use the frequency of class repetition ${ }^{21}$ as a schoolrelated medium-term outcome, since there are no standardized test scores provided in the SOEP. To measure long-term cognitive development and probable success in the labor market, we use a binary variable to measure if an individual is at least a high-track graduate. It takes the value unity, when an individual achieved the German high-track degree (Abitur) or a university degree. It takes the value zero, if otherwise. Also, we use logged values of an individuals' gross income in the year before the survey to measure labor market outcomes.

Control variables: We consider the following individual-level controls: year of birth (cohort fixed effects), a dummy for male gender, age, and a dummy whether an individual grew up in an urban region. In sensitivity analyses, we additionally use controls for the current region of living and number of siblings. Additionally, we consider mother's and father's highest education (defined by unity, if having achieved the German high-track degree or a university degree, or zero if otherwise) as family-background controls. In sensitivity analyses, we modify these variables with information on whether or not the mother and the father are academics. As another robustness test, we use these controls at the household level. ${ }^{22}$

\subsection{Descriptive statistics}

The mean values of the treatment variable, outcome and control variables are described in Table 1. As can be seen in Panel A, 417 individuals (37.5\%) in our sample were born after the reform out of a total of 1,112 individuals we observe. Slightly more than half of them were born as a firstborn and, thus, were affected by the reform (intention-to-treat effect). ${ }^{23}$ The main outcome variable, life satisfaction, tends to be higher for individuals born after the baby year reform, as seen in Panel B.

\footnotetext{
${ }^{21}$ In the GDR, class repetition was common. Thus, there is enough variance in the observations to use it as an outcome variable.

${ }^{22}$ Descriptive statistics for control variables are shown in the appendix in Table A.1.

${ }^{23}$ There are many observations for which we have information on the year of birth, but not on the month of birth. If these individuals are not born in 1986, we can include them in the sample. However, if they were born in 1986, we have to exclude them, since we need the month of birth to classify individuals born in 1986 to be treated or non-treated. Only few individuals in our sample were born in May or June of 1986. Thus, the issue of medically delaying birth to be eligible for the reform, which is subject to many papers analyzing parental leave reforms with the help of an RDD approach, is not a big concern in our analysis. However, we conduct a robustness test where we exclude 1986 to control for this issue.
} 
Table 1

Overall mean and mean comparisons of outcomes of individuals born before or after the baby year reform

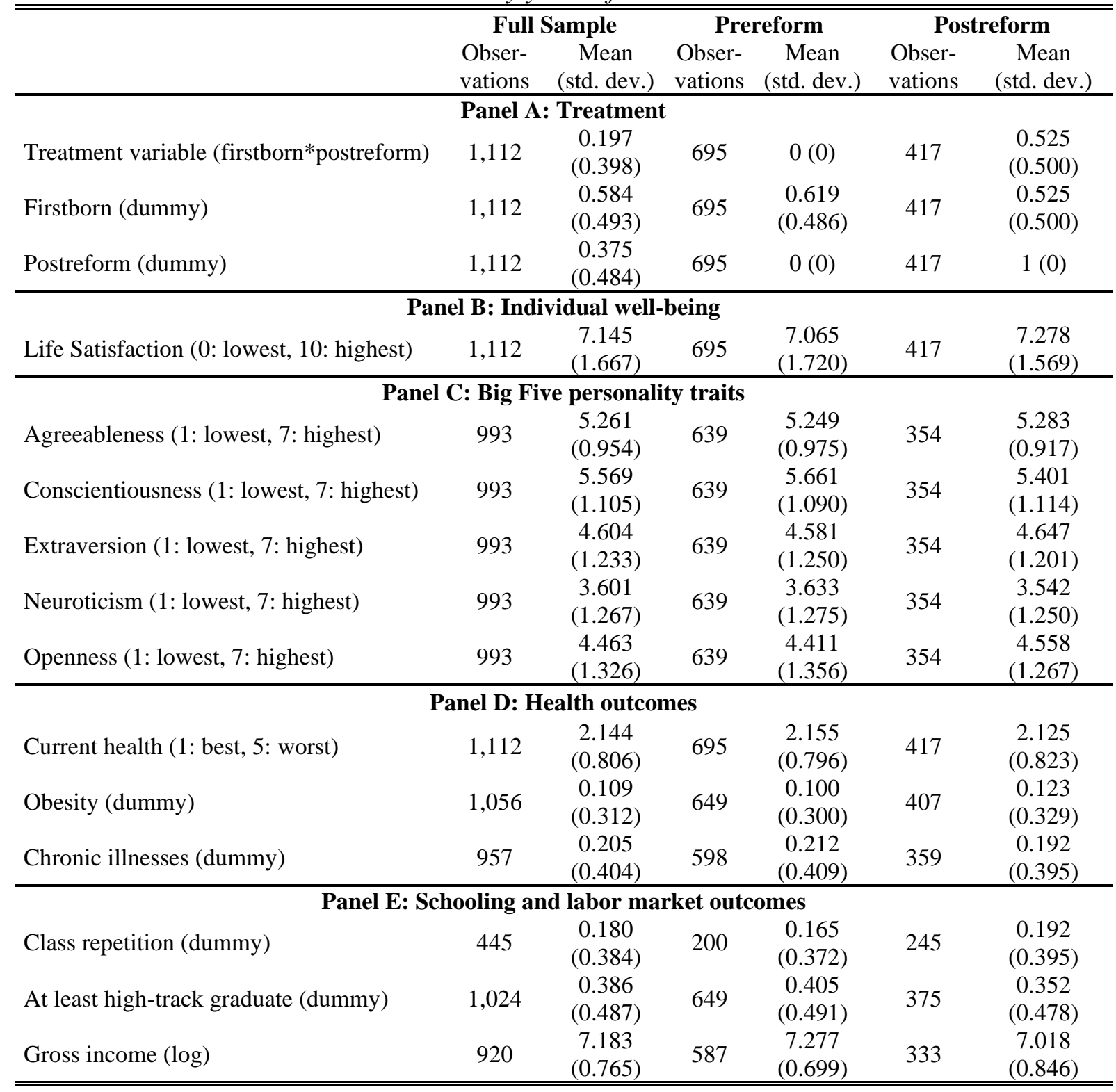

Notes: This table displays individual descriptives based on the birth cohorts 1980 to 1989 taken from SOEP waves 2000 to 2016. Panel A provides descriptive statistics on our treatment variable, the baby year parental leave reform in the GDR, adjusted to the number of observations in the regression for our main outcome of life satisfaction (Panel B). Panel C shows outcome variables of the Big Five personality traits. Panel D introduces descriptives for analyses using health outcomes, while Panel E shows descriptives on schooling and labor market outcome variables. Panel F shows control variables we use in our baseline regressions and robustness tests. All variables shown are adjusted to the sample of the main analysis using life satisfaction.

Source: Socio-Economic Panel (SOEP), data for years 1984-2016, version 33, SOEP, 2017, doi:10.5684/soep.v33. Own calculations.

In Panel $\mathrm{C}$ to $\mathrm{E}$, outcome variables to analyze potential channels are described. Compared to individuals born before the reform, individuals born after score better in terms of all Big Five personality traits (Panel C), with the exception of conscientiousness. Also, individuals born 
after the reform tend to have better health (Panel D), but worse schooling and labor market outcomes (Panel E). Worse labor market outcomes might be due to the fact that individuals born after the reform are still younger (mean: 19.8 years) than individuals born before the reform (mean: 22.8 years).

A first graphical impression of the DiD-approach for the outcome variable of life satisfaction is provided in Figure 4. The figure plots observations by year of birth to the left and to the right of the reform cut-off date ( $1^{\text {st }}$ of May 1986, vertical line) for both firstborn and later-born children before and after the reform. Before the reform, later-born individuals are more satisfied with life in adulthood than firstborns. In the year of the reform, there is a jump in life satisfaction scores for firstborn individuals, but not for later-borns. In the years after, life satisfaction of firstborn individuals is higher than life satisfaction scores of later-born individuals.

Figure 4:

Local averages for life satisfaction before and after the baby year reform

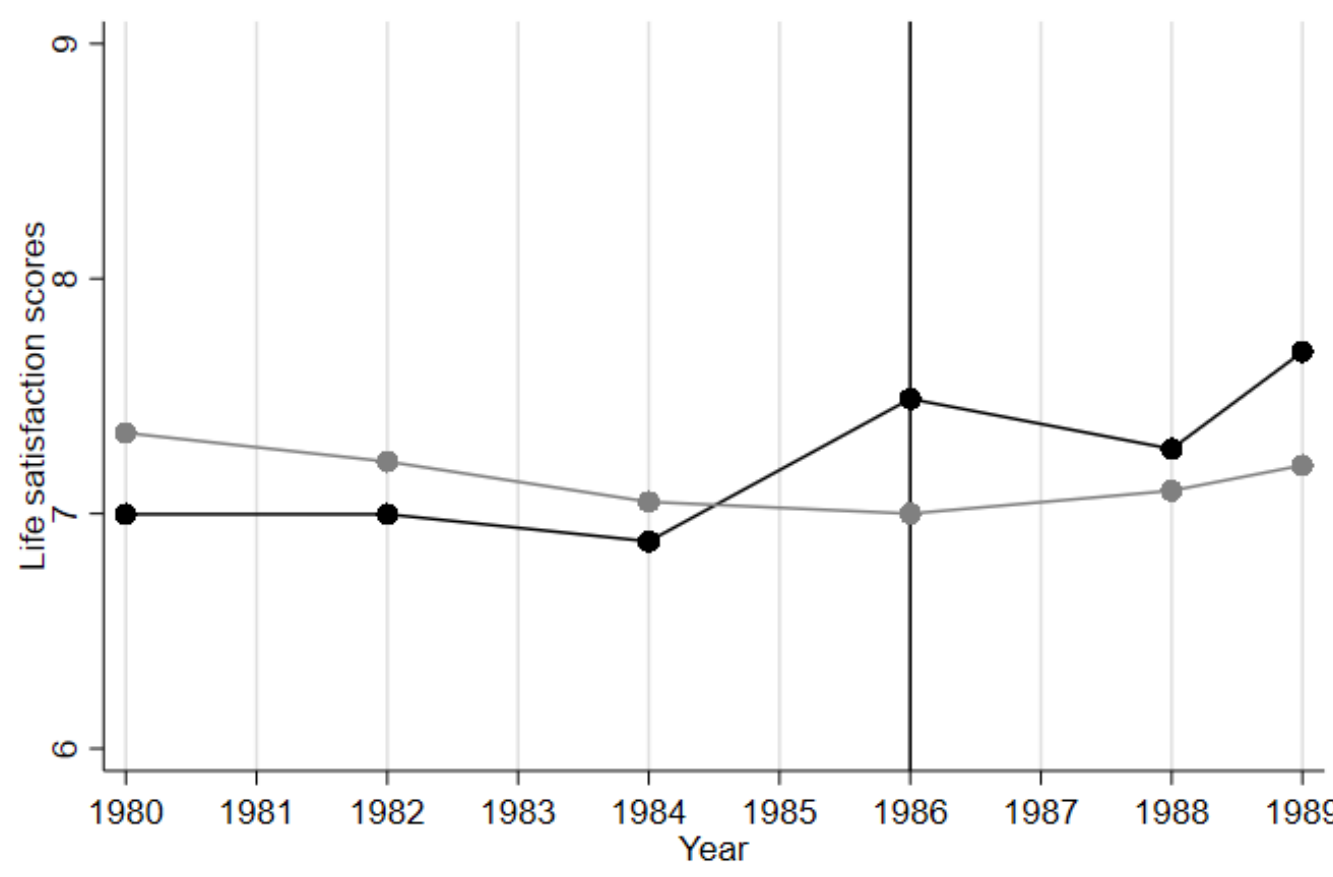

$\longrightarrow$ Firstborns: average values —— Later-borns: average values

Notes: The figure shows average values of life satisfaction plotted for firstborn (black) and later-born (grey) individuals. The vertical line indicates the time of the baby year reform on the $1^{\text {st }}$ of May 1986. Due to sample sizes for the birth cohorts, we calculated the mean for every two years. We binned the birth years 1980 and 1981 , 1982 and 1983, 1984 and 1985, as well as 1987 and 1988.

Source: Socio-Economic Panel (SOEP), data for years 1984-2016, version 33, SOEP, 2017,

doi:10.5684/soep.v33. Own calculations. 


\section{Empirical results}

\subsection{Baseline scenario}

To test whether the difference in life satisfaction scores between pre- and postreform first- and later-borns is significantly different from zero, we regress life satisfaction scores on our treatment variable, its components and a set of control variables in an OLS-estimation with heteroskedasticity-robust error terms. The estimated "eligible to the baby year reform"coefficient for the baseline specification is reported in Table 2, column (1). As Figure 4 in Section 4.2 suggested, the average life satisfaction scores between pre- and postreform firstand later-borns differ significantly from zero and increased by $33 \%$ of the standard deviation. ${ }^{24}$ Compared to the pre-reform level, life satisfaction increases by $7.8 \%$ of the pre-reform mean. ${ }^{25}$

Table 2

Effects of the baby year reform on long-term life satisfaction of children

\begin{tabular}{|c|c|c|c|c|c|c|}
\hline & Baseline & \multicolumn{5}{|c|}{ Robustness tests } \\
\hline & $\begin{array}{l}\text { (1) } \\
\text { Full sample }\end{array}$ & $\begin{array}{l}\text { (2) } \\
\text { Add. control: } \\
\text { living in West } \\
\text { Germany }\end{array}$ & $\begin{array}{l}\text { (3) } \\
\text { Add. control: } \\
\text { number of } \\
\text { siblings }\end{array}$ & $\begin{array}{c}(4) \\
\text { Without } \\
\text { birthyear } \\
\text { of } 1986 \\
\end{array}$ & $\begin{array}{c}\text { (5) } \\
\text { Birth before } \\
\text { June } 1988\end{array}$ & $\begin{array}{c}\text { (6) } \\
\text { Placebo } \\
\text { reform date } \\
\text { (May 1982) } \\
\end{array}$ \\
\hline Firstborn*postreform & $\begin{array}{c}0.550 * * * \\
(0.213)\end{array}$ & $\begin{array}{c}0.540 * * \\
(0.212)\end{array}$ & $\begin{array}{c}0.472 * * \\
(0.222)\end{array}$ & $\begin{array}{c}0.515^{* *} \\
(0.218)\end{array}$ & $\begin{array}{c}0.536 * * \\
(0.269)\end{array}$ & $\begin{array}{c}0.175 \\
(0.318)\end{array}$ \\
\hline Firstborn & $\begin{array}{c}-0.238 * \\
(0.136)\end{array}$ & $\begin{array}{l}-0.232 * \\
(0.136)\end{array}$ & $\begin{array}{l}-0.195 \\
(0.146)\end{array}$ & $\begin{array}{c}-0.254 * \\
(0.138)\end{array}$ & $\begin{array}{c}-0.235^{*} \\
(0.137)\end{array}$ & $\begin{array}{l}-0.131 \\
(0.197)\end{array}$ \\
\hline Postreform & $\begin{array}{l}-0.672 \\
(0.448)\end{array}$ & $\begin{array}{l}-0.655 \\
(0.450)\end{array}$ & $\begin{array}{l}-0.356 \\
(0.485)\end{array}$ & $\begin{array}{c}1.987 * * * \\
(0.432)\end{array}$ & $\begin{array}{l}-0.590 \\
(0.466)\end{array}$ & $\begin{array}{c}0.848 \\
(0.557)\end{array}$ \\
\hline Constant & $\begin{array}{c}5.248 * * * \\
(0.364)\end{array}$ & $\begin{array}{c}5.218 * * * \\
(0.365)\end{array}$ & $\begin{array}{c}5.265 * * * \\
(0.378)\end{array}$ & $\begin{array}{c}5.247 * * * \\
(0.367)\end{array}$ & $\begin{array}{c}5.389 * * * \\
(0.477)\end{array}$ & $\begin{array}{c}6.877 * * * \\
(0.981)\end{array}$ \\
\hline R-squared & 0.069 & 0.072 & 0.079 & 0.070 & 0.068 & 0.093 \\
\hline Observations & 1.112 & 1.112 & 1.019 & 1.048 & 913 & 537 \\
\hline $\begin{array}{l}\text { Cohort fixed effects } \\
\text { Individual controls } \\
\text { Background controls }\end{array}$ & $\begin{array}{l}\text { Yes } \\
\text { Yes } \\
\text { Yes }\end{array}$ & $\begin{array}{l}\text { Yes } \\
\text { Yes } \\
\text { Yes }\end{array}$ & $\begin{array}{l}\text { Yes } \\
\text { Yes } \\
\text { Yes }\end{array}$ & $\begin{array}{l}\text { Yes } \\
\text { Yes } \\
\text { Yes }\end{array}$ & $\begin{array}{l}\text { Yes } \\
\text { Yes } \\
\text { Yes }\end{array}$ & $\begin{array}{l}\text { Yes } \\
\text { Yes } \\
\text { Yes }\end{array}$ \\
\hline
\end{tabular}

Notes: This table displays the DiD estimates resulting from an OLS regression with life satisfaction as outcome variable (measured between ages 18 and 36), respectively, dependent on the mother's eligibility status for the baby year paid parental leave reform. Regressions include birth cohort fixed effects, individual controls such as gender, age and the survey year, as well as background controls such as maternal and paternal education and whether the individual grew up in an urban area, or not. The table shows the regression results for the pooled sample. Robust standard errors are reported in parentheses. Levels of significance: $* * * p<0.01, * * p<0.05$, $* \mathrm{p}<0.1$.

Source: Socio-Economic Panel (SOEP), data for years 1984-2016, version 33, SOEP, 2017, doi:10.5684/soep.v33. Own calculations.

${ }^{24}$ The calculation is as follows: The coefficient shown in Table 2 column (1), first row, divided by the standard deviation of life satisfaction in the full sample displayed in Table 1, Panel B, gives the named result $(0.550 / 1.667=33 \%)$.

${ }^{25}$ Life satisfaction is measured on a scale from zero to ten. The pre-reform mean is 7.065, as can be seen in Table 1 , column (4). The point estimate of life satisfaction is 0.550 , which thus gives the named result $(0.550 / 7.065=7.8 \%)$. 


\subsection{Robustness checks}

Our baseline specification does not include measures that could change in reaction to being exposed to prolonged maternal care due to the baby year reform. We additionally include such variables - currently living in West German states and number of siblings, respectively — in column (2) and (3) of Table 2. The estimated coefficient decreases only marginally after controlling for the current region of living, but standard errors become slightly smaller. When controlling for the number of siblings, however, the estimated coefficient decreases more in size, but standard errors increase. Both results remain significantly different from zero.

In columns (4) and (5), we restrict our sample. In column (4), we exclude all individuals who were born in 1986. We do this because first, there might be a slight probability that mothers postpone birth by a few days or weeks to be eligible to the reform. Second, there might have been difficulties in the first months of implementing the reform or applying for parental leave afterwards. Third, mothers of children born in the second half of 1986 might already have had a place in a child care centers for their baby, and did not want to withdraw due to social or work-related reasons. In column (5), we exclude individuals born in 1988 because of potential differences between them and other children due to the closeness of their birthday to the German reunification. However, in both specifications, the estimated coefficient remains significantly different from zero, although they slightly decrease in size and standard errors increase.

In column (6), we estimate the coefficient by using a pseudo reform date (May 1982). We chose this specific year, because, to the best of our knowledge, there were no other reforms in 1982 which might have had an influence on life satisfaction. The sample we use here was born between 1978 and 1984. Reassuringly, the difference between averages of pre- and postreform first- and later-borns is not significantly different from zero.

In Table A.3 in the appendix, we conduct four additional robustness checks by interchanging parental education variables on the one hand, and redefining treated individuals by being born from November 1985 on. ${ }^{26}$ Specifically, in columns (2) to (4), we substitute family background controls by different variables (either education on household level, or using a dummy whether parents are academics). All results remain significantly different from

\footnotetext{
${ }^{26}$ We conduct the latter robustness check, since we did not find any official information on how eligibility status was determined. Because of this, we cannot exclude the probability that mothers, whose children were as young as six months (end of pre-reform paid maternal protection) when the reform became effective, were eligible for parental leave within the framework of the baby year reform.
} 
zero. In column (5), we redefine treated individuals. Results remain significantly different from zero, and the treatment coefficient increases in size.

\subsection{Effect heterogeneity}

As a next step we stratify the model of our baseline specification in Table 2, column (1), by interacting the treatment variable with maternal education (see equation (3) in Section 3) and the individual's gender. Estimation results are displayed in Table 3. In contrast to our hypotheses stated in Section 2, there are no significant differences between average life satisfaction of individuals from low or high socioeconomic backgrounds, or between the averages of each gender.

Table 3

Effects of the baby year reform on long-term life satisfaction of children by mother's socioeconomic background and children's gender

\begin{tabular}{lccc}
\hline \hline & $\begin{array}{c}\text { Panel A } \\
\text { Full sample }\end{array}$ & $\begin{array}{c}\text { Panel B } \\
\text { Effects by socioeconomic } \\
\text { background }\end{array}$ & $\begin{array}{c}\text { Panel C } \\
\text { Effects by gender }\end{array}$ \\
\hline Firstborn*postreform*low educated mother & & 0.757 & \\
& & $(0.493)$ & \\
Firstborn*postreform*male & & & -0.0330 \\
& & & $(0.418)$ \\
Firstborn*postreform & $0.550^{* * *}$ & -0.0328 & $0.565^{*}$ \\
& $(0.213)$ & $(0.441)$ & $(0.289)$ \\
\hline R-squared & 0.069 & 0.07 & 0.069 \\
\hline Observations & 1.112 & 1.112 & 1.112 \\
\hline Cohort fixed effects & Yes & Yes & Yes \\
Individual controls & Yes & Yes & Yes \\
Background controls & Yes & Yes & Yes \\
\hline \hline
\end{tabular}

Notes: This table displays subgroup DiD estimates resulting from an OLS regression with life satisfaction as outcome variable (measured between ages 18 and 36), respectively, dependent on the mother's eligibility status for the baby year paid parental leave reform. Regressions include birth cohort fixed effects, individual controls such as gender, age and the survey year, as well as background controls such as maternal and paternal education and whether the individual grew up in an urban area, or not. Regressions in Panel B and C also include interactions of the variables firstborn and postreform with a dummy for low maternal education and a dummy for male gender of the observed individual, respectively. The table shows the regression results for the pooled sample. Robust standard errors are reported in parentheses. Levels of significance: $* * * \mathrm{p}<0.01, * * \mathrm{p}<0.05$, $* \mathrm{p}<0.1$.

Source: Socio-Economic Panel (SOEP), data for years 1984-2016, version 33, SOEP, 2017, doi:10.5684/soep.v33. Own calculations.

\subsection{Channels}

\subsubsection{Big Five personality traits}

As we discussed in Section 2.4, there might be a variety of channels that could lead to the positive effect of the baby year reform on life satisfaction. We test in this section whether the effect might be due to personality development. Results for each Big Five personality trait are 
presented in Table 4. Panel A shows results from regressions with the full sample. However, there are no effects of the reform on the Big Five personality traits of children in the long run. When stratifying the model from Panel A by socioeconomic background (Panel B) or the individual's gender (Panel C), we find differences between the averages of the particular subgroups. We see in Panel B that conscientiousness of affected individuals from high socioeconomic backgrounds decreased, but it increased for individuals from low socioeconomic backgrounds with a coefficient of $0.173 .{ }^{27}$ The negative effect on conscientiousness for individuals from high socioeconomic backgrounds is in contrast to what we expected, but the estimation has a high standard deviation. The positive effect of the reform for individuals from low socioeconomic backgrounds is in line with the hypothesis set in Section 2.4.

Table 4

Effects of the baby year reform on long-term Big Five personality traits of children

\begin{tabular}{|c|c|c|c|c|c|}
\hline & $\begin{array}{c}(1) \\
\text { Agreeableness } \\
\end{array}$ & $\begin{array}{c}(2) \\
\text { Conscientiousness } \\
\end{array}$ & $\begin{array}{c}(3) \\
\text { Extraversion }\end{array}$ & $\begin{array}{c}(4) \\
\text { Neuroticism }\end{array}$ & $\begin{array}{c}(4) \\
\text { Openness } \\
\end{array}$ \\
\hline \multicolumn{6}{|c|}{ Panel A: Full sample } \\
\hline Firstborn*postreform & $\begin{array}{c}0.103 \\
(0.128) \\
\end{array}$ & $\begin{array}{l}-0.0101 \\
(0.149) \\
\end{array}$ & $\begin{array}{c}-0.0616 \\
(0.168) \\
\end{array}$ & $\begin{array}{c}0.254 \\
(0.167) \\
\end{array}$ & $\begin{array}{c}0.218 \\
(0.177) \\
\end{array}$ \\
\hline \multicolumn{6}{|c|}{ Panel B: Effects by socioeconomic background } \\
\hline $\begin{array}{l}\text { Firstborn*postreform*low } \\
\text { educated mother }\end{array}$ & 0.182 & $0.728 * *$ & 0.253 & $-0.803 * *$ & -0.147 \\
\hline & $(0.285)$ & $(0.337)$ & $(0.385)$ & $(0.388)$ & $(0.403)$ \\
\hline Firstborn*postreform & $\begin{array}{l}-0.0333 \\
(0.244)\end{array}$ & $\begin{array}{l}-0.555^{*} \\
(0.292)\end{array}$ & $\begin{array}{l}-0.258 \\
(0.332)\end{array}$ & $\begin{array}{c}0.859 * * \\
(0.339)\end{array}$ & $\begin{array}{c}0.325 \\
(0.347)\end{array}$ \\
\hline \multicolumn{6}{|c|}{ Panel C: Effects by gender } \\
\hline Firstborn*postreform*male & $\begin{array}{c}0.289 \\
(0.256)\end{array}$ & $\begin{array}{c}0.178 \\
(0.298)\end{array}$ & $\begin{array}{c}0.118 \\
(0.334)\end{array}$ & $\begin{array}{l}-0.0866 \\
(0.334)\end{array}$ & $\begin{array}{l}0.711 * * \\
(0.354)\end{array}$ \\
\hline Firstborn*postreform & $\begin{array}{l}-0.0229 \\
(0.181) \\
\end{array}$ & $\begin{array}{l}-0.0935 \\
(0.201) \\
\end{array}$ & $\begin{array}{l}-0.122 \\
(0.243) \\
\end{array}$ & $\begin{array}{c}0.284 \\
(0.238) \\
\end{array}$ & $\begin{array}{l}-0.146 \\
(0.255) \\
\end{array}$ \\
\hline Observations & 993 & 993 & 993 & 993 & 993 \\
\hline Cohort fixed effects & Yes & Yes & Yes & Yes & Yes \\
\hline Individual controls & Yes & Yes & Yes & Yes & Yes \\
\hline Background controls & Yes & Yes & Yes & Yes & Yes \\
\hline
\end{tabular}

Notes: This table displays subgroup DiD estimates resulting from an OLS regression with the Big Five personality traits as outcome variables (measured between ages 18 and 36), respectively, dependent on the mother's eligibility status for the baby year paid parental leave reform. Regressions include birth cohort fixed effects, individual controls such as gender, age and the survey year, as well as background controls such as maternal and paternal education and whether the individual grew up in an urban area, or not. Regressions in Panel B and C also include interactions of the variables firstborn and postreform with a dummy for low maternal education and a dummy for male gender of the observed individual, respectively. Only observations are used for whom life satisfaction is available. The table shows the regression results for the pooled sample. Robust standard errors are reported in parentheses. Levels of significance: *** $p<0.01, * * p<0.05$, * $p<0.1$. Source: Socio-Economic Panel (SOEP), data for years 1984-2016, version 33, SOEP, 2017, doi:10.5684/soep.v33. Own calculations.

\footnotetext{
${ }^{27}$ The calculation is as follows: The estimated coefficient for individuals from low socioeconomic backgrounds is added to the estimated coefficient for individuals from high socioeconomic backgrounds $(-0.555+0.728=0.173)$.
} 
We also find that long-term neuroticism of (now-adult) affected children from high socioeconomic backgrounds increased, and the estimate is significant different from zero. The effect for individuals from low socioeconomic backgrounds is significantly different from the average of individuals from high socioeconomic backgrounds and close to zero. This result might be explained by literature suggesting first, that intelligent individuals tend to be more neurotic and even have a higher risk for psychological disorders than less intelligent people (Penney et al., 2014; Karpinski et al., 2018). Second, the increased time with an intelligent mother might have fostered an intergenerational transmission of neuroticism-related personality traits (Yamagata et al., 2016; Colich et al., 2017). In Panel C, effect differences between the genders are displayed. There are positive effects for males in terms of openness. This is in line with literature that found boys to be more sensitive in early life in general, and especially sensitive to early separation from the mother and low-quality external care, so that they benefit from increased maternal care in early life in terms of personality and behavior (Kottelenberg and Lehrer, 2014; Beeghly et al., 2017; Golding and Fitzgerald, 2017; Schore, 2017).

\subsubsection{Health}

In this section we test whether the increase in life satisfaction might be driven by differences in the health of treated and non-treated individuals. Estimated results are presented in Table 5. Panel A suggests that on average, individuals who were subject to the baby year reform do more often show chronic illnesses than individuals who were not subject to the reform. The effect is significantly different from zero. Since we find positive — but not significantly different from zero - effects on overall health (a negative coefficient implies that individuals rate their overall health better), our hypothesis that the environment in care centers favored health more than environment at home cannot be confirmed completely. An explanation for the increase in chronic illnesses might be that children in care centers were exposed more to different germs because of other children and thus adapted immunities more frequently than at home where no other children were present (e.g., Ball et al., 2000). Panel B displays results stratified by socioeconomic backgrounds. The estimated coefficient for individuals from high socioeconomic backgrounds suggests better overall health for these individuals. The effect is statistically different from zero and shows that for families from high socioeconomic backgrounds, the quality of environment children grew up might be higher. The difference between averages of individuals from high and low socioeconomic backgrounds is statistically different from zero. For them, the environment at home (being the counterfactual to child care 
centers) was of lower quality in terms of health development. However, the calculated coefficient is as small as 0,04 and thus, the effect size is close to zero. In terms of gender, there are no differences between females and males in terms of health as can be seen in Panel C.

Table 5

Effects of the baby year reform on long-term health of children

\begin{tabular}{lccc}
\hline \hline & $(1)$ & $(2)$ & $(3)$ \\
& Obesity & Overall health & Chronic illnesses \\
\hline \multirow{4}{*}{ Firstborn*postreform } & Panel A: Full sample & & \\
& -0.00705 & -0.0533 & $0.110^{* *}$ \\
& $(0.0406)$ & $(0.106)$ & $(0.0552)$ \\
\hline & Panel B: Effects by socioeconomic background & \\
Firstborn*postreform*low educated mother & -0.00488 & $0.405^{*}$ & -0.0425 \\
& $(0.0846)$ & $(0.246)$ & $(0.132)$ \\
Firstborn*postreform & -0.00225 & $-0.365^{*}$ & 0.142 \\
& $(0.0664)$ & $(0.216)$ & $(0.116)$ \\
\hline & Panel C: Effects by gender & & \\
Firstborn*postreform*male & -0.0207 & -0.294 & -0.0192 \\
& $(0.0809)$ & $(0.209)$ & $(0.113)$ \\
Firstborn*postreform & 0.00448 & 0.0960 & 0.119 \\
& $(0.0575)$ & $(0.147)$ & $(0.0815)$ \\
\hline Observations & 1.056 & 1.112 & 957 \\
\hline Cohort fixed effects & Yes & Yes & Yes \\
Individual controls & Yes & Yes & Yes \\
Background controls & Yes & Yes & Yes \\
\hline \hline
\end{tabular}

Notes: This table displays subgroup DiD estimates resulting from an OLS regression with different health outcomes (measured between ages 18 and 36), respectively, dependent on the mother's eligibility status for the baby year paid parental leave reform. Regressions include birth cohort fixed effects, individual controls such as gender, age and the survey year, as well as background controls such as maternal and paternal education and whether the individual grew up in an urban area, or not. Regressions in Panel B and C also include interactions of the variables firstborn and postreform with a dummy for low maternal education and a dummy for male gender of the observed individual, respectively. Only observations are used for whom life satisfaction is available. The table shows the regression results for the pooled sample. Robust standard errors are reported in parentheses. Levels of significance: $* * * \mathrm{p}<0.01, * * \mathrm{p}<0.05, * \mathrm{p}<0.1$.

Source: Socio-Economic Panel (SOEP), data for years 1984-2016, version 33, SOEP, 2017, doi:10.5684/soep.v33. Own calculations.

\subsubsection{Schooling and labor market outcomes}

We also test whether the increase in life satisfaction might be driven by the channel of schooling and labor market outcomes. However, as Table 6 suggests, there are no significant effects different from zero of the baby year reform on schooling or labor market outcomes, which is in line with a large part of previous literature and our drawn hypotheses in Section 2.4 . 
Table 6

Effects of the baby year reform on long-term schooling and labor market outcomes of children

(1)

Class repetition

At least high-track graduate

Gross income $(\log )$

Panel A: full sample

Firstborn*postreform

$-0.0368$

0.0330

0.116

(0.0760)

(0.0601)

(0.103)

Panel B: effects by socioeconomic background

Firstborn*postreform*low educated mother

$-0.0583$

0.206

0.0923

Firstborn*postreform

(0.152)

(0.151)

(0.260)

0.00716

$-0.123$

0.0455

(0.127)

(0.134)

(0.235)

Panel C: effects by gender

Firstborn*postreform*male

$\begin{array}{lll}0.177 & 0.0445 & 0.0361\end{array}$

(0.146)

(0.122)

(0.207)

Firstborn*postreform

$-0.120$

0.0129

0.0997

$(0.0838)$

$(0.0853)$

(0.159)

\begin{tabular}{lccc}
\hline Observations & 445 & 1.024 & 920 \\
\hline Cohort fixed effects & Yes & Yes & Yes \\
Individual controls & Yes & Yes & Yes \\
Background controls & Yes & Yes & Yes \\
\hline \hline
\end{tabular}

Notes: This table displays subgroup DiD estimates resulting from an OLS regression with different schooling outcomes (class repetition measured between ages 16 and 19) for ages of 18 to 36, dependent on the mother's eligibility status for the baby year paid parental leave reform. Regressions include birth cohort fixed effects, individual controls such as gender, age and the survey year, as well as background controls such as maternal and paternal education and whether the individual grew up in an urban area, or not. Regressions in Panel B and $\mathrm{C}$ also include interactions of the variables firstborn and postreform with a dummy for low maternal education and a dummy for male gender of the observed individual, respectively. Only observations are used for whom life satisfaction is available. The table shows the regression results for the pooled sample. Robust standard errors are reported in parentheses. Levels of significance: $* * * \mathrm{p}<0.01, * * \mathrm{p}<0.05, * \mathrm{p}<0.1$. Source: Socio-Economic Panel (SOEP), data for years 1984-2016, version 33, SOEP, 2017, doi:10.5684/soep.v33. Own calculations.

\section{Discussion and alternative channels}

Apart from the channels introduced in Sections 5.4.1 to 5.4.3, there might be other mechanisms that could have influenced the life satisfaction of individuals who were subject to the baby year reform of 1986. If fertility was affected by the reform of 1986 and families decided to have a second or third child after the reform more often than before the reform, treated firstborns might be less likely to be an only child. ${ }^{28}$ This might influence life satisfaction in two directions. On the one hand, they could be more satisfied with life due to possible positive experiences of having one or more siblings. On the other hand, they might be less satisfied with life by having more siblings due to higher competition in childhood with other children, a worse financial

\footnotetext{
${ }^{28}$ Conrad et al. (1995) shows that there was just a very slight, not sizable increase in total fertility rates in 1987. Fertility continued to decrease thereafter.
} 
situation of parents, etc. We therefore run a regression with the number of siblings as an outcome variable. Results are shown in Table A.3 in the Appendix. We find negative effects of the reform on the number of siblings of children. The effect is statistically different from zero, but very small (individuals who were subject to the baby year reform have 0.25 siblings less than individuals not subject to the reform).

Families might have also been more likely to move to West German states after the reunification when having only one child, since it is shown in the literature that families are more mobile the less children they have (e.g., Fischer and Malmberg, 2001; Long, 1972). The baby year reform was very close to the German reunification, and if families with an only child were more likely to move to West German states after the German reunification, there might be a probability that the relocation to West German states had an effect on an individual's life satisfaction. On the one hand, individuals might be more satisfied with life due to better perspectives in West German states after the German reunification. On the other hand, individuals might be less satisfied with life since they had to leave behind childhood friends and other family members such as grandparents. The results are also displayed in Table A.3 where we find no effects significantly different from zero of the reform on the probability of living in West German states in adulthood. Thus, this channel does not drive our results on life satisfaction.

\section{Conclusion}

In this paper, we study the baby year reform of the GDR and its impact on long-term life satisfaction of affected (now-adult) children. The reform prolonged paid parental leave by six months so that mothers could stay at home with their baby for twelve instead of six months after birth. Because of the almost $100 \%$ labor force participation rate of women and standardized full-day care for almost all children, the evaluation of the GDR reform does not face problems of selection of women into the labor market and insufficient or heterogeneous child care supply, which is in contrast to many other studies on parental leave reforms. We analyze the birth cohorts 1980 to 1989 of the SOEP survey by applying a DiD-approach, making use of a very specific timing of the GDR's baby year reform. From 1976 on, mothers with at least two children were entitled to a twelve-month parental leave; from 1986 on, all mothers, including those of firstborn children, were entitled to this longer leave period. We thus compare the trend of outcome variables of firstborn children with the trend of outcome variables of later-born children to measure the causal effect of the reform. 
This paper focuses on the effects of the baby year reform on long-term subjective wellbeing (measured by overall life satisfaction) of children. This measure captures the sum of effects on other individual dimensions such as health, personality and education or labor market success. To the best of our knowledge, subjective well-being has not yet been analyzed in parental leave literature as a potential outcome that is impacted by parental leave reforms. Yet, there are many reasons why subjective well-being of children is an important outcome to look at when evaluating parental leave reforms. First, child psychology literature suggests that spending more time with the mother within the first year of life has a positive impact on a child's personality development (Bowlby 1969). Second, well-being has been become an important outcome variable in recent economic literature (e.g. Kahneman and Krueger, 2006; Clark et al., 2008; Deaton and Stone, 2013; Benjamin et al., 2019). On the one hand, literature shows that subjective well-being is an important and more direct way to measure welfare. On the other hand, responses to questions about subjective well-being capture aspects of an individual's health, overall neurological functioning and other characteristics. It can also predict future behavior (Kahneman and Krueger, 2006).

Our results reveal that spending more time with the mother in the whole first year of life - compared to spending six months with the mother and six months in a childcare center matters for individuals in the long run. The prolongation of parental leave by six months has positive effects on subjective well-being measured by life satisfaction, which increases by $33 \%$ of the standard deviation and corresponds to an increase by $7.8 \%$ of the pre-reform mean. Results are robust throughout a variety of sensitivity analyses and similar for females and males, as well as individuals from high and low socioeconomic backgrounds.

We also analyze whether the increase in life satisfaction might be driven by other channels that could have been influenced by the baby year reform, such as personality development, health, educational or labor market outcomes. We find that the positive effect of the reform on life satisfaction might be partly explained by a positive development of personality traits of individuals from low socioeconomic backgrounds and boys. For individuals from high socioeconomic backgrounds, it might be partly explained by a positive health development.

Our findings emphasize that individuals are affected differently by parental leave reforms and that the effects vary by socioeconomic background and gender. However, as diverse as the effects on different dimensions such as personality development and health are, all individuals seem to benefit in terms of life satisfaction from staying at home with their mother for the complete first year of life. 


\section{Sources}

Baker, M. and K.S. Milligan (2008). Maternal employment, breastfeeding, and health: Evidence from maternity leave mandates. Journal of Health Economics, 27(4), pp. 87187.

Ball, T.M., Castro-Rodriguez, J.A., Griffith, K.A., Holberg, C.J., Martinez, F.D. and A.L. Wright (2000). Siblings, Day-Care Attendance, and the Risk of Asthma and Wheezing during Childhood. The New England Journal of Medicine, 343, August 24, 2000, pp. 53843.

Beeghly, M., Partridge, T., Tronick, E., Muzik, M., Mashhadi, M.R., Boeve, J.L. and J.L. Irwin (2017). Associations between early maternal depressive symptom trajectories and toddlers' felt security at 18 months: are boys and girls at differential risk? Infant Mental Health Journal, 38(1), pp. 53-67.

Belsky, J., Lowe Vandell, L., Burchinal, M., Clarke-Stewart, K.A., McCartney, K. and M. Tresch Owen (2007). Are There Long-Term Effects of Early Child Care? Child Development, Vol. 78(2), pp. 681-701.

Benjamin, D.J., Cooper, K.B., Heffetz, O. and M. Kimball (2019). A Well-Being Snapshot in a Changing Word. AEA Papers and Proceedings, 109, May 2019, pp. 344-49.

Berger, L.M., Hill, J. and Waldfogel, J. (2005). Maternity leave, early maternal employment and child health and development in the US. Economic Journal, 115(501), pp. F29-47.

Bettinger, E., Haegeland, T. and M. Rege (2014). Home with Mom: The Effects of Stay-atHome Parents on Children's Long-Run Educational Outcomes. Journal of Labor Economics, 32(3), pp. 403-67.

Bowlby, J. (1969). Attachment and Loss. Hogarth, London.

Braun, U. and T. Klein (1995). Der berufliche Wiedereinstieg der Mutter im Lebensverlauf der Kinder. In: Nauck, B. and H. Bertram (eds.). Kinder in Deutschland: Lebensverhältnisse von Kindern im Regionalvergleich. DJI: Familien-Survey 5. Leske + Budrich, Opladen, 1995.

Bullinger, L.R. (2019). The Effect of Paid Family Leave on Infant and Parental Health in the United States. Journal of Health Economics, 66(July 2019), pp. 101-16. 
Büttner, T. and W. Lutz (1990). Estimating Fertility Responses to Policy Measures in the German Democratic Republic. Population and Development Review, 16(3), pp. 539-555.

Cardis, E., Krewski, D., Boniol, M., Drozdovitch, V., Darby, S.C., Gilbert, E.S., Akiba, S., Benichou, J., Ferlay, J., Gandini, S., Hill, C., Howe, G., Kesminiene, A., Moser, M., Sanchez, M., Storm, H., Voisin, L. and P. Boyle (2006). Estimates of the cancer burden in Europe from radioactive fallout from the Chernobyl accident. International Journal of Cancer, 119(6), April 2006, pp. 1224-35.

Carneiro, P., Løken, K. and K.G. Salvanes (2011). A Flying Start? Maternity Leave Benefits and Long Run Outcomes of Children. Journal of Political Economy, 123(2), DOI: $10.1086 / 679627$.

Clark, A.E., Frijters, P. and M.A. Shields (2008). Relative Income, Happiness, and Utility: An Explanation for the Easterlin Paradox and Other Puzzles. Journal of Economic Literature, 46(1), March 2008, pp. 95-144.

Colich, N.L., Ho, T.C., Ellwood-Lowe, M.E., Foland-Ross, L.C., Sacchet, M.D., LeMoult, J.L. and I.H. Gotlib (2017). Like mother like daughter: putamen activation as a mechanism underlying intergenerational risk for depression. Social Cognitive and Affective Neuroscience, 12(9), pp. 1480-89, https://doi.org/10.1093/scan/nsx073.

Conrad, C., Lechner, M. and W. Werner (1995). The Fall of the East German Birth Rate After Unification: Crisis or Means of Adaptation? Program for the Study of Germany and Europe Working Paper Series 5.6.

Danzer, N. and V. Lavy (2017). Paid Parental Leave and Children's Schooling Outcomes. The Economic Journal, 128(608), pp. 81-117, https://doi.org/10.1111/ecoj.12493.

Deaton, A. and A.A. Stone (2013). Two Happiness Puzzles. American Economic Review, 103(3), May 2013, pp. 591-97.

Dustmann, C. and U. Schönberg (2011). Expansions in Maternity Leave Coverage and Children's Long-Term Outcomes. American Economic Journal: Applied Economics, 4(3), pp. 190-224.

Felfe, C. and Hsin, A. (2012). Maternal Work Conditions and Child Development. Economics of Education Review, 31(6), pp. 1037-57, http://dx.doi.org/10.1257/app.4.3.190. 
Felfe, C. and Zierow, L. (2018). From dawn till dusk: Implications of full-day care for children's development. Labour Economics Vol. 55, December 2018, pp. 259-81.

Fischer, P.A. and G. Malmberg (2001). Settled People Don’t Move: On Life Course and (Im)Mobility in Sweden. International Journal of Population Geography, 7, pp- 357-71.

Galbraith, J., Choi, J. and A. Shams (2017). "An Index of inter-industry wage inequality" by Nathalie Scholl: A Reply. University of Texas Inequality Project Working Paper \#74, October 26,2017.

Gerlitz, J.Y. and J. Schupp (2005). Zur Erhebung der Big-Five-basierten Persönlichkeitsmerkmale im SOEP [Assessment of Big-Five-based personality traits in the SOEP]. Berlin, Germany: Deutsches Institut für Wirtschaftsforschung.

Goebel, J., Grabka, M.M., Liebig, S., Kroh, M., Richter, D., Schröder, C. and J. Schupp (2019). The German Socio-Economic Panel Study (SOEP). Jahrbücher für Nationalökonomie und Statistik / Journal of Economics and Statistics, 239(2), pp. 345-60. doi: https://doi.org/10.1515/jbnst-2018-0022.

Golding, P. and H.E. Fitzgerald (2017). Psychology of boys at risk: Indicators from 0-5. Infant Mental Health Journal, 38(1), pp. 5-14.

Groeben, N. (2011). Braucht Man(n) einen finanziellen Anreiz für die Familienarbeit? Über den Einfluss finanzieller und gesellschaftlicher Rahmenbedingungen auf die Väterbeteiligung an Elternzeit und Familienarbeit am Beispiel Elterngeld. FU Berlin.

Han, W. (2005). Maternal nonstandard work schedules and child cognitive outcomes. Child Development, 76(1), pp. 137-54.

Helwig, G. (1987). Frau und Familie: Bundesrepublik Deutschland und DDR. Köln.

Höckner, M. (1995). Der Staat hat viele Väter - wo bleiben die Mütter? In: Nauck, B. and H. Bertram (eds.). Kinder in Deutschland: Lebensverhältnisse von Kindern im Regionalvergleich. DJI: Familien-Survey 5. Leske + Budrich, Opladen, 1995.

Huebener, M., Kuehnle, D. and C.K. Spiess (2018). Parental Leave Policies and SocioEconomic Gaps in Child Development: Evidence from a Substantial Benefit Reform Using Administrative Data. IZA Discussion Paper No. 11794, August 2018. 
Israel, A. and I. Kerz-Rühling (eds.) (2008): Krippen-Kinder in der DDR - Frühe Kindheitserfahrungen und ihre Folgen für die Persönlichkeitsentwicklung und Gesundheit, 2008, pp. 11-32.

Johnson, R., Kalil, A. and R. Dunifon (2005). Employment patterns of less-skilled workers: Links to children's behavior and academic progress. Demography, 49(2), pp. 747-72.

Kahneman, D. and A.B. Krueger (2006). Developments in the Measurement of Subjective Well-Being. Journal of Economic Perspectives, 20(1), Winter 2006, pp. 3-24.

Karpinski, R.I., Kinase Kolb, A.M., Tetreault, N.A. and T.B. Borowski (2018). High intelligence: A risk factor for psychological and physiological overexcitabilities. Intelligence, 66, January-February 2018, pp. 8-23.

Kottelenberg, M.J. and S.F. Lehrer (2014). The Gender Effects of Universal Child Care in Canada: Much ado about Boys? Queen's University Working Paper.

Lalive, R. and J. Zweimüller (2009). How Does Parental Leave Affect Fertility and Return to Work? Evidence from Two Natural Experiments. The Quarterly Journal of Economics, 124(3), pp. 1363-402.

Loeb, S., Fuller, B., Kagan, S.L. and B. Carrol (2004). Child Care in Poor Communities: Early Learning Effects of Type, Quality, and Stability. Child Development, Vol. 75(1), pp. 4765.

Long, L.H. (1972). The Influence of Number and Ages of Children on Residential Mobility. Demography, 9(3), pp. 371-82.

McLoyd, V. (1998). Socioeconomic disadvantage and child development. American Psychologist, 53(2), pp. 185-204.

Nentwig-Gesemann, I. (1999). Krippenerziehung in der DDR. Alltagspraxis und Orientierungen von Erzieherinnen im Wandel. Springer Fachmedien Wiesbaden GmbH 1999.

Obertreis, G. (1986). Familienpolitik in der DDR 1945 - 1980. Forschungstexte Wirtschaftsund Sozialwissenschaften, Vol. 17. Springer Fachmedien, Wiesbaden.

OECD (2018). Enrolment rates in early childhood education and care services, 0- to 2-yearolds. Chart PF3.2.A. 
OECD (2019). Labour force participation rate, by sex and age group. https://stats.oecd.org/index.aspx?queryid=54741

Penney, A. M., Miedema, V.C. and D. Mazmanian (2014). Intelligence and emotional disorders: Is the worrying and ruminating mind a more intelligent mind? Personality and Individual Differences, 74, February 2015, pp. 90-93.

Rammstedt, B. and O.P. John (2007). Measuring personality in one minute or less: A 10-item short version of the Big Five Inventory in English and German. Journal of Research in Personality, 41(2007), pp. 203-212.

Rasmussen, A.W. (2007). The Long-Term Effect on Children of Increasing the Length of Parents' Birth-Related Leave. Aarhus School of Business, Department of Economics Working Paper No. 07-11.

Raver, C. (2003). Does work pay psychologically as well as economically? The role of employment in predicting depressive symptoms and parenting among low-income families. Child Development, 74(6), 1720-36.

Ruhm, C.J. (2000). Parental leave and child health. Journal of Health Economics, 19(6), pp. 931-60.

Schore, A.N. (2017). All our sons: The developmental neurobiology and neuroendocrinology of boys at risk. Infant Mental Health Journal, 38(1), pp. 15-52.

Winkler, G. (ed.) (1990). Frauenreport '90, Verlag Die Wirtschaft Berlin GmbH

Yamagata, B., Murayama, K., Black, J.M., Hancock, R., Mimura, M., Yang, T.T., Reiss, A.L. and F. Hoeft (2016). Female-Specific Intergenerational Transmission Patterns of the Human Corticolimbic Circuitry. Journal of Neuroscience, 36(4), pp. 1254-60, https://doi.org/10.1523/JNEUROSCI.4974-14.2016

Zwiener, K. (1994). Kinderkrippen in der DDR, Verlag Deutsches Jugendinstitut, Munich. 


\section{Appendix}

Table A.1

Descriptive statistics including control variables

\begin{tabular}{|c|c|c|c|}
\hline & Observations & Mean & Std. dev. \\
\hline \multicolumn{4}{|l|}{ Panel A: Treatment } \\
\hline Treatment variable (firstborn*postreform) & 1,112 & 0.197 & 0.398 \\
\hline Firstborn (dummy) & 1,112 & 0.584 & 0.493 \\
\hline Postreform (dummy) & 1,112 & 0.375 & 0.484 \\
\hline \multicolumn{4}{|l|}{ Panel B: Individual well-being } \\
\hline Life Satisfaction (0: lowest, 10: highest) & 1,112 & 7.145 & 1667 \\
\hline \multicolumn{4}{|l|}{ Panel C: Big Five personality traits } \\
\hline Agreeableness (1: lowest, 7: highest) & 993 & 5.261 & 0.954 \\
\hline Conscientiousness (1: lowest, 7: highest) & 993 & 5.569 & 1.105 \\
\hline Extraversion (1: lowest, 7 : highest) & 993 & 4.604 & 1.233 \\
\hline Neuroticism (1: lowest, 7: highest) & 993 & 3.601 & 1.267 \\
\hline Openness (1: lowest, 7 : highest) & 993 & 4.463 & 1.326 \\
\hline \multicolumn{4}{|l|}{ Panel D: Health outcomes } \\
\hline Current health (1: best, 5 : worst) & 1,112 & 2.144 & 0.806 \\
\hline Obesity (dummy) & 1,056 & 0.109 & 0.312 \\
\hline Chronic illnesses (dummy) & 957 & 0.205 & 0.404 \\
\hline \multicolumn{4}{|l|}{ Panel E: Schooling and labor market outcomes } \\
\hline Class repetition (dummy) & 445 & 0.180 & 0.384 \\
\hline At least high-track graduate (dummy) & 1,024 & 0.386 & 0.487 \\
\hline Gross income $(\log )$ & 920 & 7.183 & 0.765 \\
\hline \multicolumn{4}{|l|}{ Panel F: Control variables } \\
\hline Male gender (dummy) & 1,112 & 0.489 & 0.500 \\
\hline Year of birth (1980-1989) & 1,112 & 1984,546 & 2.975 \\
\hline Grew up in urban area (dummy) & 1,112 & 0.683 & 0.466 \\
\hline Grew up in urban area (missing dummy) & 1,112 & 0.009 & 0.094 \\
\hline Number of siblings $(0-11)$ & 1,019 & 1.364 & 1.206 \\
\hline Living in West German states (dummy) & 1,112 & 0.289 & 0.453 \\
\hline Mother is at least high-track graduate (dummy) & 1,112 & 0.244 & 0.430 \\
\hline Mother is at least high-track graduate (missing dummy) & 1,112 & 0.014 & 0.120 \\
\hline Mother is an academic (dummy) & 1,112 & 0.182 & 0.386 \\
\hline Mother is an academic (missing dummy) & 1,112 & 0.030 & 0.170 \\
\hline Father is at least high-track graduate (dummy) & 1,112 & 0.215 & 0.411 \\
\hline Father is at least high-track graduate (missing dummy) & 1,112 & 0.042 & 0.201 \\
\hline Father is an academic (dummy) & 1,112 & 0.167 & 0.373 \\
\hline Father is an academic (missing dummy) & 1,112 & 0.062 & 0,241 \\
\hline At least one parent is a high-track graduate (dummy) & 1,112 & 0.308 & 0.462 \\
\hline $\begin{array}{l}\text { At least one parent is a high-track graduate (missing } \\
\text { dummy) }\end{array}$ & 1,112 & 0.008 & 0.090 \\
\hline At least one parent is an academic (dummy) & 1,112 & 0.260 & 0.439 \\
\hline At least one parent is an academic (missing dummy) & 1,112 & 0.012 & 0.108 \\
\hline
\end{tabular}


Notes: This table displays individual descriptives based on the birth cohorts 1980 to 1989 taken from SOEP waves 2000 to 2016. Panel A provides descriptive statistics on our treatment variable, the baby year parental leave reform in the GDR, adjusted to the number of observations in the regression for our main outcome of life satisfaction (Panel B). Panel C shows outcome variables of the Big Five personality traits. Panel D introduces descriptives for analyses using health outcomes, while Panel E shows descriptives on schooling and labor market outcome variables. Panel F shows control variables we use in our baseline regressions and robustness tests. All variables shown are adjusted to the sample of the main analysis using life satisfaction.

Source: Socio-Economic Panel (SOEP), data for years 1984-2016, version 33, SOEP, 2017, doi:10.5684/soep.v33. Own calculations.

Table A.2

Regressions for alternate channels: number of siblings and current region of living

\begin{tabular}{lcc}
\hline \hline & Number of siblings & Lives in a West German state \\
\hline Firstborn*postreform & $-0.263^{*}$ & 0.0457 \\
Firstborns & $(0.152)$ & $(0.0573)$ \\
& $-0.385^{* * *}$ & -0.0261 \\
Postreform & $(0.0895)$ & $(0.0370)$ \\
& 0.411 & -0.0809 \\
Constant & $(0.394)$ & $(0.137)$ \\
& $0.591 * * *$ & 0.137 \\
R-squared & $(0.215)$ & $(0.0999)$ \\
Observations & 0.096 & 0.060 \\
Cohort fixed effects & 1,019 & 1,112 \\
Individual controls & Yes & Yes \\
Background controls & Yes & Yes \\
\hline \hline
\end{tabular}

Notes: This table displays the DiD estimates for two placebo tests resulting from an OLS regression with outcome variables for number of siblings and current region of living — either East or West German Laender - (measured between ages 18 and 36), respectively, dependent on the mother's eligibility status for the baby year paid parental leave reform. Regressions include birth cohort fixed effects, individual controls such as gender, age and the survey year, as well as background controls such as maternal and paternal education and whether the individual grew up in an urban area, or not. Only observations are used for whom life satisfaction is available. Robust standard errors are reported in parentheses. Levels of significance: $* * * \mathrm{p}<0.01, * * \mathrm{p}<0.05, * \mathrm{p}<0.1$.

Source: Socio-Economic Panel (SOEP), data for years 1984-2016, version 33, SOEP, 2017, doi:10.5684/soep.v33. Own calculations. 
Table A.3

Robustness checks: definition changes of parental education and eligibility for the outcome of long-term life satisfaction of children

\begin{tabular}{|c|c|c|c|c|c|}
\hline & \multirow{2}{*}{$\frac{\text { Baseline }}{(1)}$} & \multicolumn{4}{|c|}{ Robustness checks } \\
\hline & & (2) & (3) & (4) & (5) \\
\hline & Full sample & $\begin{array}{c}\text { Definition } \\
\text { change: at least } \\
\text { one parent is a } \\
\text { high-track } \\
\text { graduate }\end{array}$ & $\begin{array}{c}\text { Definition } \\
\text { change: mother } \\
\text { and father are } \\
\text { academics }\end{array}$ & $\begin{array}{c}\text { Definition } \\
\text { change: at least } \\
\text { one parent is } \\
\text { an academic }\end{array}$ & $\begin{array}{l}\text { Eligibility: } \\
\text { firstborns } \\
\text { from } \\
\text { November } \\
1985 \text { on } \\
\end{array}$ \\
\hline \multirow[t]{2}{*}{ Firstborn*postreform } & $0.550 * * *$ & $0.546 * * *$ & $0.541 * *$ & $0.536 * *$ & $0.658 * * *$ \\
\hline & $(0.213)$ & $(0.211)$ & $(0.211)$ & $(0.211)$ & $(0.201)$ \\
\hline \multirow[t]{2}{*}{ Firstborn } & $-0.238 *$ & $-0.245^{*}$ & $-0.232 *$ & $-0.234 *$ & $-0.266^{*}$ \\
\hline & $(0.136)$ & $(0.136)$ & $(0.136)$ & $(0.136)$ & $(0.141)$ \\
\hline \multirow[t]{2}{*}{ Postreform } & -0.672 & -0.704 & $-0.748 *$ & -0.713 & 0.0904 \\
\hline & $(0.448)$ & $(0.444)$ & $(0.448)$ & $(0.443)$ & $(0.371)$ \\
\hline \multirow[t]{2}{*}{ Constant } & $5.248 * * *$ & $5.244 * * *$ & $5.230 * * *$ & $5.227 * * *$ & $5.262 * * *$ \\
\hline & $(0.364)$ & $(0.362)$ & $(0.365)$ & $(0.362)$ & $(0.361)$ \\
\hline $\mathrm{R}$-squared & 0.069 & 0.069 & 0.068 & 0.070 & 0.072 \\
\hline Observations & 1,112 & 1,112 & 1,112 & 1,112 & 1,158 \\
\hline Cohort fixed effects & Yes & Yes & Yes & Yes & Yes \\
\hline Individual controls & Yes & Yes & Yes & Yes & Yes \\
\hline Background controls & Yes & Yes & Yes & Yes & Yes \\
\hline
\end{tabular}

Notes: This table displays the DiD estimates resulting from an OLS regression with life satisfaction as outcome variable (measured between ages 18 and 36), respectively, dependent on the mother's eligibility status for the baby year paid parental leave reform. Regressions include birth cohort fixed effects, individual controls such as gender, age and the survey year, as well as background controls such as maternal and paternal education and whether the individual grew up in an urban area, or not. The table shows the regression results for the pooled sample. Robust standard errors are reported in parentheses. Levels of significance: $* * * \mathrm{p}<0.01, * * \mathrm{p}<0.05$, $* \mathrm{p}<0.1$.

Source: Socio-Economic Panel (SOEP), data for years 1984-2016, version 33, SOEP, 2017, doi:10.5684/soep.v33. Own calculations. 